Trinity College

Trinity College Digital Repository

Faculty Scholarship

Spring 1989

Musical and Dramatic Structure in the Opera Buffa Finale

John Platoff

Trinity College, john.platoff@trincoll.edu

Follow this and additional works at: https://digitalrepository.trincoll.edu/facpub

Part of the Musicology Commons 


\section{Musical and Dramatic Structure in the Opera Buffa Finale*}

JOHN PLATOFF

$\mathrm{T}_{\mathrm{h}}$

he study of the opera buffa of the late eighteenth century has for many years been virtually synonymous with the study of Mozart's mature operas. Scholars have recently shown an increased interest in the operas of Haydn, but operatic works by the leading contemporaries of these two great figures remain almost completely unknown. ${ }^{1}$ It is thus not surprising that what is believed to be true about the finale in opera buffa applies quite well to Mozart's finales, but far less well to those of Paisiello, Salieri, Martin y Soler, and

Volume $7 \cdot$ Number $2 \cdot$ Spring 1989

The Journal of Musicology $\odot 1989$ by the Regents of the University of California

* A shorter version of this paper was presented at the annual meeting of the American Musicological Society, Louisville, Kentucky, in October 1983. I am grateful to Leonard B. Meyer, Ruth Montgomery, Gary Tomlinson, and Piero Weiss for many useful suggestions.

' Studies of Mozart's Viennese operatic contemporaries have been very limited in number. Those that deal in some detail with musical matters (as opposed to biographical or bibliographical issues) include Hermann Abert, W. A. Mozart: neubearbeitete und erweiterte Ausgabe von Otto Jahns Mozart, 8th ed., 2 vols. (Leipzig, 1973-75), in particular the chapter on "Opera Buffa," I, 332-82; idem, "Paisiellos Buffokunst und ihre Beziehungen zu Mozart," Archiv für Musikwissenschaft I (1918-19), 402-21, repr. in Abert, Gesammelte Schriften und Vorträge, ed. Friedrich Blume (Halle, 1929), pp. 365-96; Judith Ann Anderson, "The Viennese Operas of Stephen Storace" (Ph.D. diss., Catholic University, 1972); Rudolph Angermüller, Antonio Salieri: sein Leben und seine weltlichen Werke unter besonderer Berücksichtigung seiner 'grossen' Opern, 3 vols. (Munich, 1971); Francesco Blanchetti, "Tipologia musicale dei concertati nell'opera buffa di Giovanni Paisiello," Rivista italiana di musicologia XIX (1984), 234-6o; Alfred Einstein, "A 'King Theodore' Opera," in Einstein, Essays in Music (New York, 1956), pp. 191-96; Alberto Ghislanzoni, Giovanni Paisiello: Valutazioni critiche rettificate (Rome, 1969); Lothar Riedinger, "Karl von Dittersdorf als Opernkomponist," Studien zur Musikwissenschaft II (1914), 21 2-349; and Edith Hays Walton-Myers, “Antonio Salieri's La Cifra: The Creation of a Late Eighteenth Century Opera” (Ph.D. diss., Northwestern University, 1977). 
the other composers writing Italian comic opera in Vienna in the 178 os. $^{2}$

This essay, based on an examination of the finales of Mozart's operatic contemporaries in Vienna, will attempt to characterize the buffo finale more accurately than has until now been possible and correct certain misconceptions about the principles on which it is built. At the same time such an investigation reveals the limitations of basing an understanding of Viennese opera on the works of Mozart alone. And it illustrates the possibilities of an essentially new approach to this repertory: the critical evaluation of Mozart's operas, for the first time, within the stylistic context provided by a detailed knowledge of the operatic works of his contemporaries.

The most fundamental misconception about the buffo finale concerns the nature and degree of its formal organization. It is widely thought that the number and arrangement of the movements in a finale create a unified, high-level structure in the piece as a whole. A further claim is that each of the movements or sections exhibits a clear formal and tonal design. ${ }^{3}$ But neither of these views is accurate, if we consider the finales of all the opere buffe written for Vienna in the 1780 . While finales invariably display overall tonal closure-they start and end in the same key - they do not generally give evidence of more detailed structural planning in either the thematic or tonal relationships among the movements. ${ }^{4}$ (Oft-studied examples such as the finale to Act II of Figaro must be counted as exceptions in this respect.) As for the individual movements of Viennese buffo finales, they cannot be under-

${ }^{2}$ Because of Joseph II's "deutsche Singspiel" project, which had begun in 1778 and continued for several years, an Italian opera company was re-established at the Burgtheater only in April ${ }_{1783}$. From that time until January 1790, when Cosi fan tutte was first performed, there were approximately 75 opere buffe performed in Vienna. Most of these, however, were originally written for and performed in other cities, chiefly in Italy. Only 20 works were original opere buffe premiered in Vienna. For a list of these, see the Appendix.

3 These views may be found in three studies of Mozart's operatic finales: Alfred O. Lorenz, "Das Finale in Mozarts Meisteropern," Die Musik XIX (1926-27), 62 1-32; Hans Engel, "Die Finali der Mozartschen Opern," Mozart-Jahrbuch 1954, pp. 113-34; and Denton Rossell, "The Formal Construction of Mozart's Operatic Ensembles and Finales" (Ph.D. diss., George Peabody College for Teachers, 1955). They also occur in more general discussions of the finale, such as Anna Amalie Abert, "Italian Opera," The New Oxford History of Music, vol. 7, The Age of Enlightenment: 1745-179o, ed. Egon Wellesz and Frederick Sternfeld (London, 1973), p. $5^{6}$.

4 Tonal relationships are not, of course, completely ignored. But composers focused their attention on the tonal juxtapositions between successive movements of a finale, rather than on more high-level planning. For a more detailed discussion, see John Platoff, "Music and Drama in the opera buffa Finale: Mozart and his Contemporaries in Vienna, 1781-1 79o" (Ph.D. diss., University of Pennsylvania, 1984), pp. 402-23. 
stood in terms of the sort of high-level formal schemes associated with instrumental movements-on the contrary, they are routinely throughcomposed, and occasionally even begin and end in different keys. ${ }^{5}$ Studies of the operatic finales of Mozart have sought out sonata- or rondolike structures in various sections (at times perhaps more eagerly than is justified by the music) ${ }^{6}$ The movements of finales by his contemporaries, though, show much less interest in such highly organized structures. The type of movement in which tonal and thematic planning are closely linked to create a clear high-level organization is virtually never found in buffo finales, outside of a few examples in Mozart's operas.

If an analytic approach based on abstract formal principles does not succeed in clarifying the structure of the buffo finale, an approach derived from an understanding of the libretto and its organization is much more revealing. This avenue has been relatively little explored, probably because of the widespread, if implicit, belief that the events of the drama are only loosely tied to the finale, rather than being the crucial factor that dictates its organization. In the words of Michael F. Robinson, the buffo finale was

built up of a chain of musical sections, each possessing its individual style, its own speed and its own time signature. The evolving drama contributed to its over-all coherence .... Precisely where the moments of change from one section to the next came, and how many sections there were, depended on the composer. ${ }^{7}$

In fact, the dramatic and poetic organization of the libretto plays a far greater role in structuring a finale than has been recognized. The composer's choices as to the number of sections in a finale and the points of articulation between them were largely guided by cues in the libretto,

5 Approximately three-quarters of the individual sections in the buffo finales written for Vienna in the 178 os close in the same key in which they began, usually after one or more modulations to fifth-related keys. Nearly all the others close in a key a fifth higher or lower than the original tonic. Tonal motion within sections tends to be unobtrusive, without any highlighting of points of arrival. In cases where the original key returns, it is rarely articulated in any conspicuous fashion, as is the case in most Classic instrumental movements.

6 For example, Siegmund Levarie, Mozart's Le Nozze di Figaro: A Critical Analysis (Chicago, 1952), characterizes the opening duet of the finale to Act II of Figaro as a sonata form without development (p. 109), despite the absence of any recapitulation of the main thematic material. Engel, "Die Finali," disagrees, calling it a sonata form with a short development whose recapitulation is made by the second theme (p. 126). Abert, W.A.Mozart, had more loosely characterized it as "freely bipartite" ("vollständig frei zweiteilig," II, 270). This duet and the opening section of the fourth act finale of Figaro (mm. 1-50) have been particular favorites for formal analysis, by Levarie, Abert, Wye Jamison Allanbrook (in Rhythmic Gesture in Mozart: Le nozze di Figaro and Don Giovanni [Chicago, $1983])$, and others.

7 Michael F. Robinson, Naples and Neapolitan Opera (Oxford, 1972), p. $23^{6}$. 
cues of a conventional nature that appear in one opera buffa after another. To understand more accurately how a finale is organized we must examine the structure of the text.

Let us begin with two familiar observations about the buffo finale. It has long been known that, while finales depict dramatic action, they also present passages of emotional expression-moments in which characters react to plot developments, or simply express their feelings. The presence of both active and expressive passages is in fact a hallmark of the finale. ${ }^{8}$

The second observation may seem equally commonplace. It is that scenes within finales are consistently constructed so as to begin with a dialogue-a succession of solo speeches for the various characters-and conclude with a tutti passage, in which all the characters join. Hans Engel calls this means of organization the "duet principle," and points to numerous examples in Mozart's finales. ${ }^{9}$

But if these two features of the buffo finale-the distinction between action and expression, and the tendency of sections to begin with dialogue and conclude with ensemble singing - are widely understood, the connection between them has largely escaped notice. And it is precisely this connection that provides the key to the organization of the finale, an organization that the librettist created and upon which the composer depended. ${ }^{10}$

Simply put, most scenes in a finale comprise two parts: the first, active portion is written in dialogue, while the concluding portion, an expressive response to the preceding action, is written as a tutti. ${ }^{11}$ The text of the finale as a whole consists of a succession of "cycles" of action and

${ }^{8}$ See for example Edward Dent, Mozart's Operas, 2nd ed. (London, 1947), pp. 72-73. Both Rossell, "The Formal Construction," p. 11, and Blanchetti, "Tipologia," p. 256, have also pointed out the interruption of the dramatic action of finales by passages of expressive comment.

In the case of Rossini, according to Philip Gossett, finales consist of "kinetic" sections, in which "action takes place ... or emotional positions are developed," and "static" ones, in which "emotions or situations are contemplated." But the separation between the two types, in which successive musical movements are alternately kinetic or static, is much more rigid than in the earlier Viennese finale. See "The 'Candeur virginale' of 'Tancredi'," Musical Times CXV (1971), 327.

9 Engel, "Die Finali," pp. 115 ff. See also Rossell, "The Formal Construction," p. 21 , and Blanchetti, "Tipologia," p. 256.

10 In many cases, of course, composers must have worked with their librettists in the organization of an operatic text. Mozart's large role in the working-out of the librettos to Idomeneo and Die Entführung, for example, is amply illustrated in his correspondence with his father.

"Here and in what follows, I will use the word "scene" to mean "dramatic situation." This is somewhat narrower than the usage found in librettos of the period, which mark changes of scene only when a character enters or leaves. 
expression, in each of which the active dialogue is followed by, and concluded by, an expressive tutti. ${ }^{12}$ Points of articulation in the libretto occur after the end of each expressive passage, setting it off from the next active passage.

Such points of articulation are often marked by changes of poetic meter, as is well known. But librettists used other devices as well, including changes in the location of the action, the entrances or exits of characters, or simply a sudden shift in the direction of the plot. Whatever the method, the articulations occur after expressive tuttis, creating a series of closed units that begin with action and conclude with expression.

These cycles are the building-blocks of the buffo finale. Composers relied on them as a basis for the division of the finale into discrete musical sections. Most often, each cycle in the libretto was set as a single movement, although occasionally the active passage might be spread over two movements. Only rarely was an expressive passage detached from its preceding active passage-and this separation was reserved for particular highpoints when the composer wanted to slow the dramatic pace, a subject to which I will return later.

These principles may be seen in Table 1, which summarizes the finale to Act I of Il burbero di buon cuore by Martin y Soler and Da Ponte. As indicated by the vertical brackets in the "Text" column, the libretto of the finale contains eight action-expression cycles. Five of these cycles are set within single musical sections, so that the end of the expressive tutti coincides with the end of the section. In two other cases (sections 1-2 and 8-9) an action begun in one section continues and concludes in the next, for reasons having to do with the specific details of the drama. ${ }^{13}$ (Sections 5 and 11 , consisting only of expression, and the unusual splitting of a cycle between action and expression in sections 9 and 10 will be considered below.) As Table 1 shows, the end of each cycle in the finale is articulated by a change in poetic meter, the entrance or exit of one or more characters, or both. ${ }^{14}$

12 See, for example, three successive scenes in the finale to Act I of Mozart and Da Ponte's Cosi fan tutte ( $\mathrm{mm} .62-136,137-218$, and 219-291 respectively), each of which comprises an active dialogue and an expressive tutti.

13 In section 1 Ferramondo asks Dorval to marry Angelica, Ferramondo's niece. The livelier Allegro non troppo of section 2 begins as Dorval completes the action by agreeing to the marriage, and the expressive tutti (here a duet) follows immediately. In sections 8 and 9 , the change to Presto coincides with a deflection in the action: Ferramondo enters his room in conversation with Dorval and is shocked and angry to find Valerio hiding there. His explosion of surprise and rage occurs in the new tempo, followed by a tutti expressing his anger and everyone else's terror.

${ }_{14}$ The Act II finale of Figaro is organized quite similarly (for a table see Platoff, "Music and Drama," p. 68). Of its eight musical sections, six set a single cycle; the two exceptions are cases in which, as in Il burbero, action beginning in one section is continued and concluded in the next. 
THE JOURNAL OF MUSICOLOGY
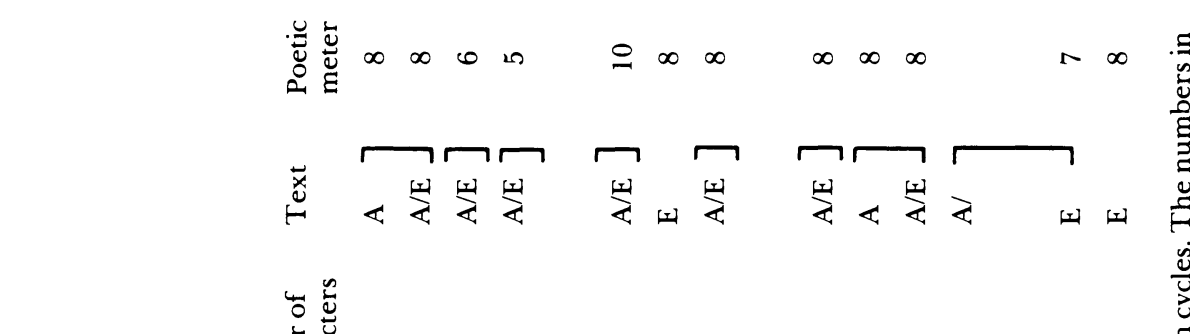

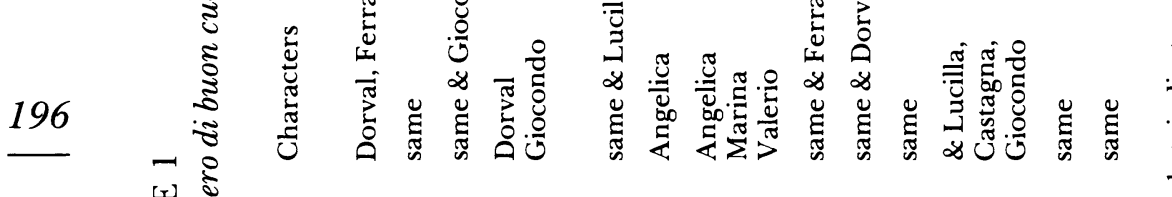

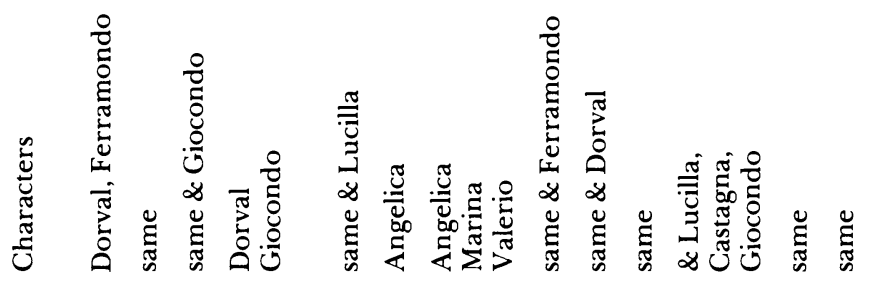

(1) ङ

$\infty$

$\varangle$<smiles>CCCC</smiles>

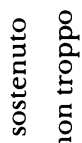

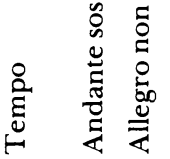

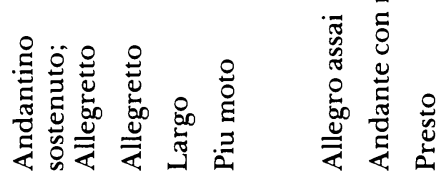

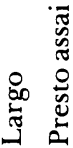

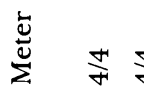

$\frac{m}{\infty} \quad \frac{\pi}{4} \frac{\pi}{\pi} \frac{a}{\pi}$

$\frac{m}{\mathrm{a}}$

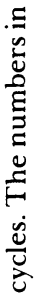

:

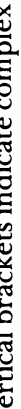

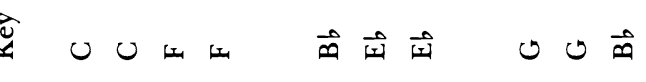

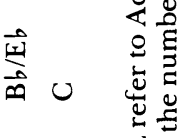

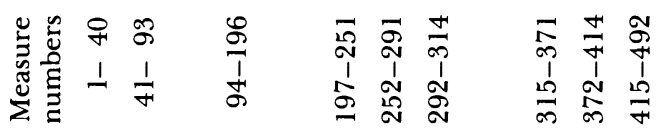

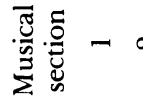

$-\infty \sigma$

$\begin{array}{ll}0 & 0 \\ 20 & 0 \\ 1 & 1 \\ \infty & 0 \\ \% & 0\end{array}$

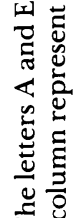

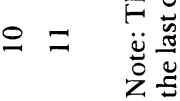


Martin y Soler's finale typifies the way composers relied on the dramatic organization of the text in structuring the music of a buffo finale. Most movements or sections are settings of a single action-expression cycle, and where the cycle ends (after the expressive tutti), the movement ends. Thus the most important musical articulations in the finale - the breaks between movements-are aligned with the points of articulation that occur in the text between cycles. And most movements have two parts: they begin with an active dialogue, and conclude with an expressive tutti. But the influence of textual organization on musical structure in the finale goes still further. The distinction between active and expressive passages is important not only because composers based their musical sections on the action-expression cycle, but because they used clearly different musical styles, reflecting different dramatic goals, to set the two types of passages.

Settings of active passages reflect an overriding concern with continuity, with a musical flow that keeps the drama moving forward. Continuity is important because of the length of active textsthey are typically three or four times longer than the corresponding expressive texts ${ }^{15}$ - and because of the nature of the plots. A finale invariably brings the action of the story to a climax, and the events leading up to it are most effective when presented in an atmosphere of confusion and turmoil. Much of the comedy in a buffo finale derives from the sense that the characters are overwhelmed by a rapid succession of events, and active passages convey a sense of breathlessness ideally suited to the action of the story.

The concern with continuity is manifested both in the harmonic organization of active passages and in their vocal style. Example 1, from the finale to Act I of Salieri and Da Ponte's Il ricco d'un giorno, illustrates the kind of harmonic patterning common in active passages, one in which the internal organization of each musical period stresses continuity. The two eight-measure periods presented here both conclude with strong $\mathrm{ii}_{6}$-V-I cadences. But within each period, the first three phrases rely on a repeated alternation between tonic and dominant. In an alternation between I and V chords, the effect of continuity overshadows the closure created by each V-I progression. So the use of this alternation pattern, a common one in active passages, creates periods whose internal structure is only weakly articulated; continuity is maximized, and

${ }^{15}$ For instance, the short scene between Masetto and Zerlina that opens the finale to Act I of Don Giovanni contains sixteen lines, all but the last four of which are the active passage. In the three cycles from the Act I finale of Cosi cited in note 12, the active passages contain 56 lines collectively, the expressive passages only 17 . 
EXAM PLE 1. Salieri and Da Ponte: Il ricco d'un giorno, Finale to Act I, section 2, mm. 24-40

(voices and bass-line only).
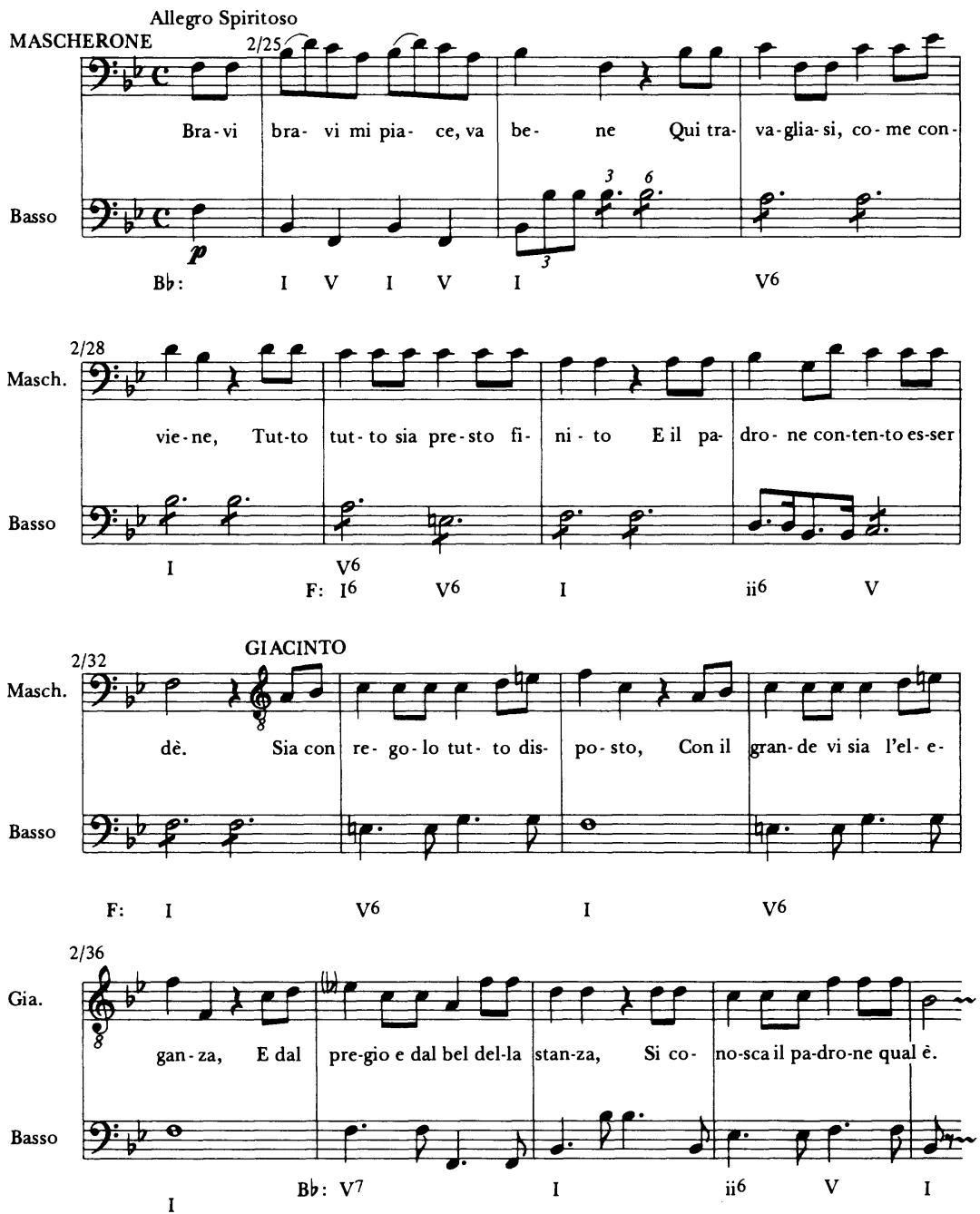

full subdominant (or $\mathrm{ii}_{6}$ )-dominant-tonic progressions are reserved for the ends of periods. The two periods, it should be noted, reflect the structure of the text, which is in two quatrains. While the length of speeches in active passages varies, composers normally set longer speeches-those that are structured as quatrains or other stanzas-as musical periods, while setting shorter ones more freely and variably. 
The vocal style of the example also reflects the importance of continuity. The text is set syllabically and without any repetition of words or phrases, while the ongoing rhythmic motion takes precedence over the expressive highlighting of individual lines. The rhythmic and metric regularity here is actually very great. All eight phrases are two measures long and employ almost exactly the same

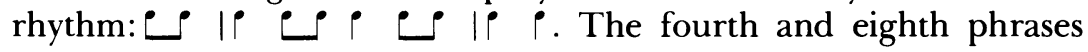
vary only in that their final measures contain a half-note rather than two quarters, since the poetic line is truncated and hence one syllable shorter.

This mechanical regularity of rhythm, a feature of many active passages, derives from the fact that normal lines of Italian poetry (versi piani) conclude with an accented syllable followed by a weak one. Composers placed nearly every phrase so that the final accented syllable of a line falls on the downbeat, followed by the last syllable on an afterbeat (except in truncated lines, which have no afterbeats). Each line begins as far back in the preceding measure or measures as necessary to arrive properly at the downbeat. Typically this involves starting on a weak beat, so that the entire phrase functions as an upbeat to the last two syllables and strong closure occurs at the end of the phrase. This convergence on the downbeat (which occurs in every phrase of the example) contributes both to the impression of a declamatory vocal style and, because of the constant sense of upbeat moving to downbeat, to a high level of rhythmic energy. Moreover, it normally results in a weak connection between successive phrases, and thus in a style which is choppy rather than lyrical. ${ }^{16}$

In other respects as well the vocal lines are not very lyrical; they rely heavily on repeated chord tones and much less often on conjunct melodic motion. The latter occurs primarily in the first three phrases for Giacinto, which also contain the only non-chord tones in the entire example: the B-flats in measures 32 and 34 , and Ds in measures 33, 35, and 36 . The other phrases lack a sense of melodic direction, since they do nothing more than outline the underlying harmony. All these features create a declamatory style that gives this passage a rather neutral, narrative quality. Like simple recitative, it moves forward rapidly but at the expense of any distinctive emotional characterization.

A central feature of active passages, and one that distinguishes them from expressive passages (and from other lyric movements, such as

\footnotetext{
${ }^{16}$ It is not simply the move to and through a downbeat that has a declamatory effect, but the beginning of most phrases on an upbeat. Because of the accent pattern of Italian poetry, nearly all lines end across a downbeat; but in more lyrical musical settings, lines of text may begin on strong beats, or be linked into longer phrases. It is their separation and the fact that they begin on an upbeat that makes them declamatory.
} 
arias), is their greater reliance on orchestral patterns to provide both continuity and musical interest. It seems appropriate for at least two reasons that the orchestral accompaniment do more than merely supply the beat and the harmony. The frequent absence of melodic interest in the vocal parts seems to call for an independent melodic contribution by the orchestra. And a prominent instrumental accompaniment can provide rhythmic continuity during the regular breaks between the short vocal phrases of active passages. ${ }^{17}$

In many active passages, the music played by the orchestra is organized by a short motive played over and over. The simple orchestral figure normally recurs with some harmonic or melodic variation, but retains a consistent rhythmic shape. Above this additively organized pattern, the singers present their lines in short phrases largely devoid of lyricism or real melodic interest. This technique has been observed in the finales of Piccinni and Paisiello, ${ }^{18}$ but it is actually far more widespread, occurring in the finales of nearly all the composers working in Vienna in the 1780 s.

Example 2 is a sampling of the kind of motives employed in this style. Parts A and B are from Paisiello and Casti's Il re Teodoro in Venezia,

$200 \mathrm{C}$ and $\mathrm{D}$ from Figaro. The examples differ in some respects-B, for instance, has little or no melodic profile-but the essential similarities are quite clear. Each motive works at two levels: the length of the figure itself, and its organization into a longer and harmonically complete unit. In Part B, the figure is only an eighth-note long, but it is used four times to create a two-measure idea that moves I-V and returns to I at the start of the next repetition: here again is the tonic-dominant alternation discussed earlier. The principle is the same in Part A, though the whole motive is two measures long and the alternation is between $I$ and $V_{6}$. In the two examples from Figaro (Parts $\mathrm{C}$ and D) the length of the motivic figure varies, but in each case it is organized into an alternation pattern. In motivically organized passages like these the harmonic motion is largely between $\mathrm{I}$ and $\mathrm{V}$, with full cadences employing the subdominant occurring only sparingly, to mark the ends of periods.

The length of the motive contributes substantially to the sense of musical pace in each passage. Example $2 \mathrm{C}$, for instance, comes from one of the most breathless sections of Mozart's finale. This is both because of

${ }_{17}$ See Robinson, Neapolitan Opera, pp. 234-35 and 256-57; and Hermann Abert, W. A. Mozart, I, 345 and 355 .

18 Hermann Abert, W. A. Mozart, I, 355 and $362-63$, with examples of the orchestral motives used by each of the two composers. See also Hermann Abert, "Paisiellos Buffokunst," p. 391, and Blanchetti, "Topologia," pp. 244-45.

The motivic technique is by no means limited merely to active sections of finales, but appears in other parts of opere buffe as well. See Anna Amalie Abert, New Oxford History, p. 57 . 
EX A M P LE 2A. Paisiello and Casti: Il re Teodoro in Venezia,

Finale to Act II, section 1, mm. 30-34.

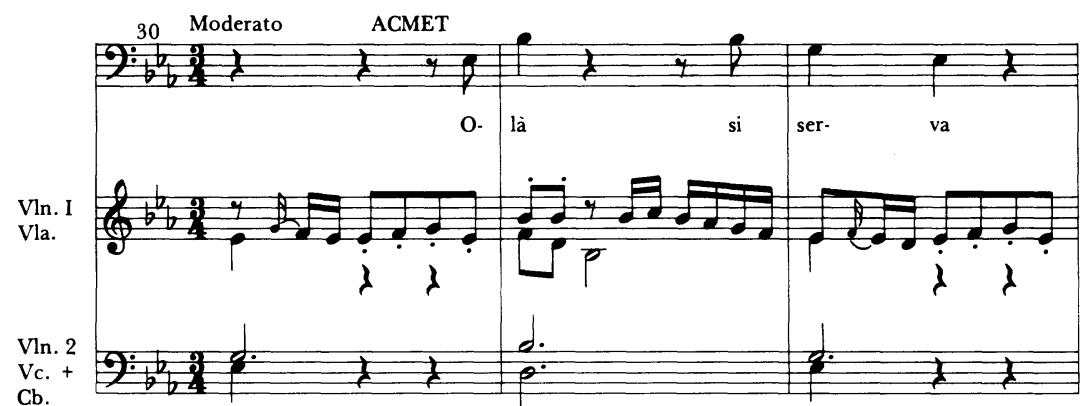

Eb: L I V6 $\sim\llcorner$

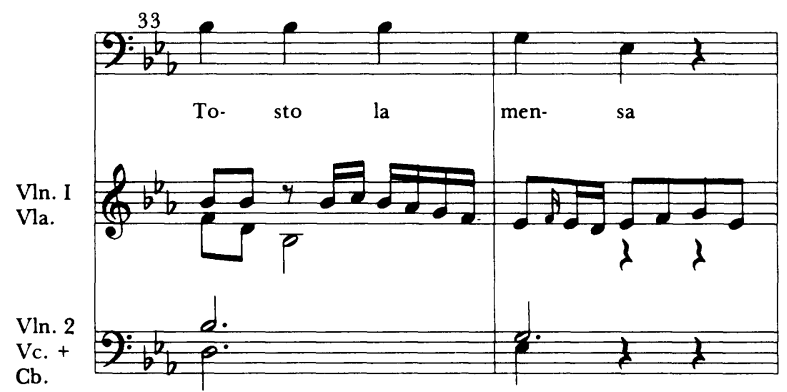

V6 I

the tempo-Allegro molto-and because of the rhythmic energy of the one-measure figure: the three slurred eighths moving to a quarter and the offbeat sfzorzandos and sixteenths create a strong motion from upbeat to downbeat. But the fast pace is also due to the harmonic rhythm, with the alternation between tonic and dominant occurring every measure. In contrast, Example $2 \mathrm{D}$ is in a slower tempo and the motivic figure is two measures long, without any particular rhythmic drive. In fact, the repeated pattern of three eighth-notes in the middle of each unit makes it seem more static. The pace here is quite slow, even agonizingly so, emphasizing the difficult situation Figaro is in. ${ }^{19}$ And the slower harmonic rhythm, with tonic-dominant alternation occurring at the two-measure level rather than every measure, plays a key role in creating this slower pace.

19 He is attempting to describe the papers he supposedly dropped while jumping into the garden. 
EX A M PL 2B. Il re Teodoro, Finale to Act I, section 4, mm. 1-5.

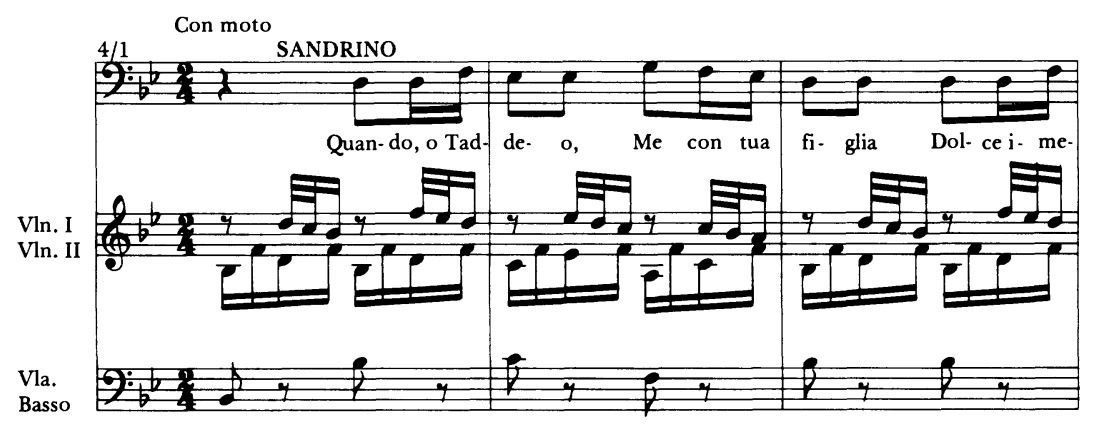

$\mathrm{Bb}$ : I V \lrcorner$\underline{I}$

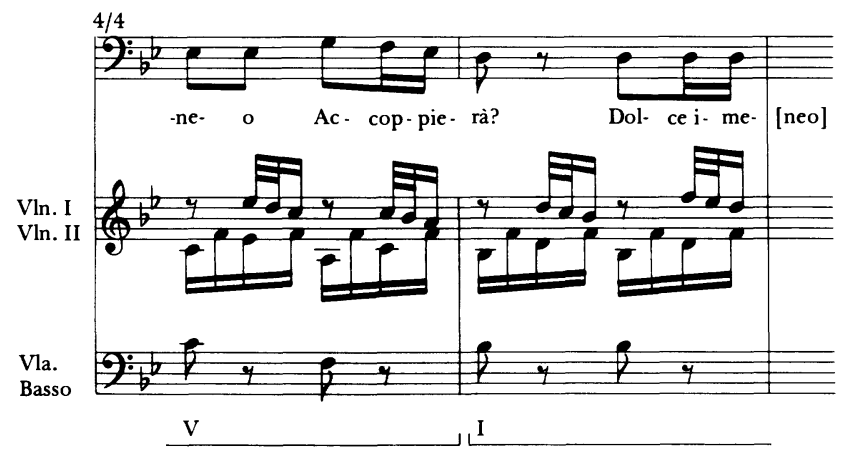

Not all active passages rely on orchestral accompaniments as tightly organized as the motivic patterns just described..$^{20}$ The majority, in fact, employ more flexible and varying accompaniments. They may use an orchestral motive at times, but in general they are constructed more freely, with the instrumental parts supporting the voices in a more traditional way. An excerpt from the finale to Act I of Il marito indolente, by Giacomo Rust and Caterino Mazzolà, shows a free accompaniment that relies on simple motives flexibly employed to support the vocal line and maintain rhythmic energy (see Example 3). Motive $x$ (m. 19) is used in measures in which the vocal line pauses, enlivening the rhythm by means of the sixteenth-notes beginning off the beat. It appears at first in successive measures and then, to accompany two-measure vocal

${ }^{20}$ In a small number of cases, orchestral accompaniments are even more tightly organized: a few active passages show a true parlante style, with simple recitative-like vocal lines above a very regular orchestral melody. The best-known example is the minuet from the finale to Act I of Don Giovanni (mm. 218-51). 
E X M P LE 2C. Mozart and Da Ponte: Le nozze di Figaro, Finale to Act IV, mm. 121-25.
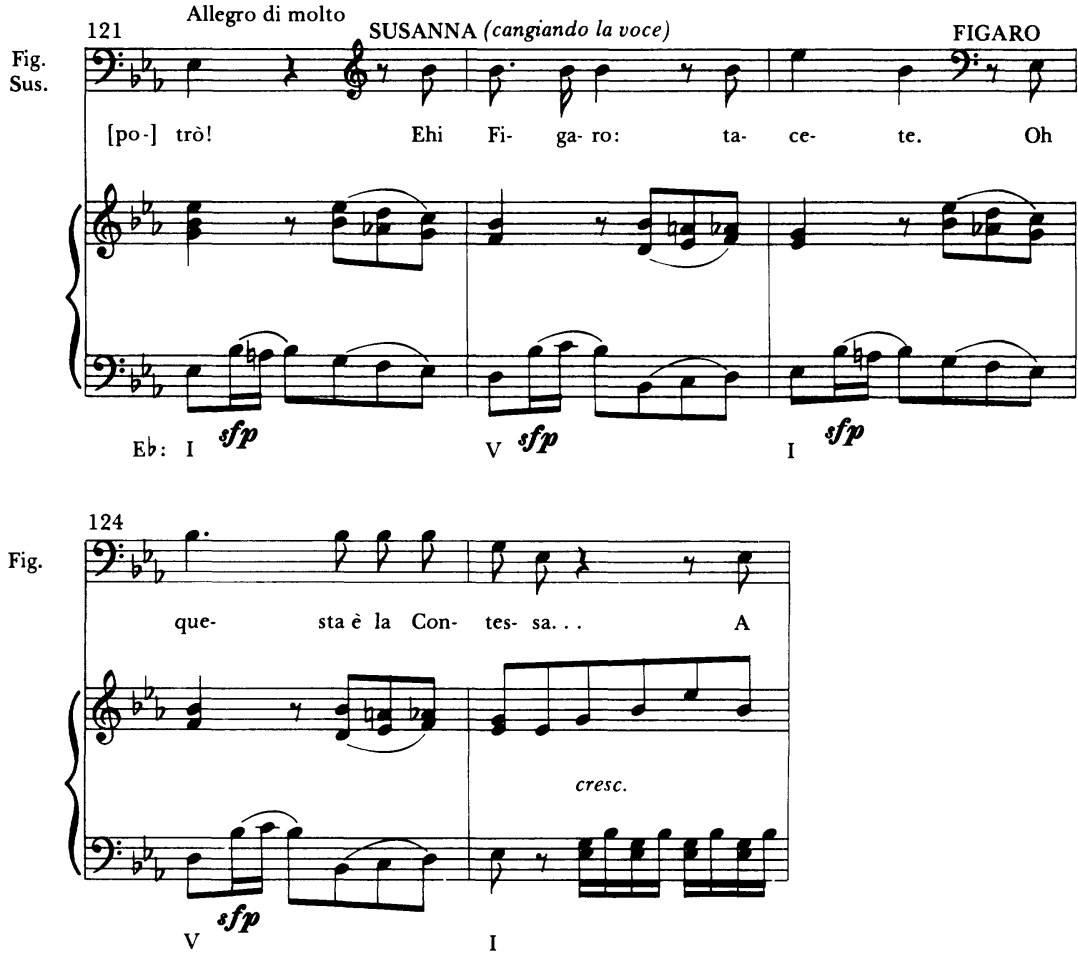

phrases, in alternate ones (mm. 23, 25, 27). After Reginella concludes in measure 33, the figure continues to appear at the ends of vocal phrases (for example in $\mathrm{mm} .37$ and 41 ). Another motive is varied in pitch contour but consistently features an attack on the second eighth-note of the measure (see $y$ in $\mathrm{mm}$. $33 \mathrm{ff}$, and a similar rhythm in other measures). Like $x$, this pattern moves from a weak to a strong beat, stressing the ongoing motion of the music. At other points the accompaniment drops the orchestral motives and doubles the vocal parts (as at mm. 30-33).

Though the continuity of this passage depends more on the voices than on the orchestra, the role of the accompaniment is still central to the sense of musical energy and pace. The orchestral writing stresses rhythmic elements above all, and it complements the vocal lines by maintaining the ongoing pulse when the latter reach points of relaxation. The vocal lines themselves, despite occasional lyrical moments, are in general nearly as declamatory as those of the Salieri example above. 
EX A M PLE 2D. Figaro, Finale to Act II, mm. 605-13.

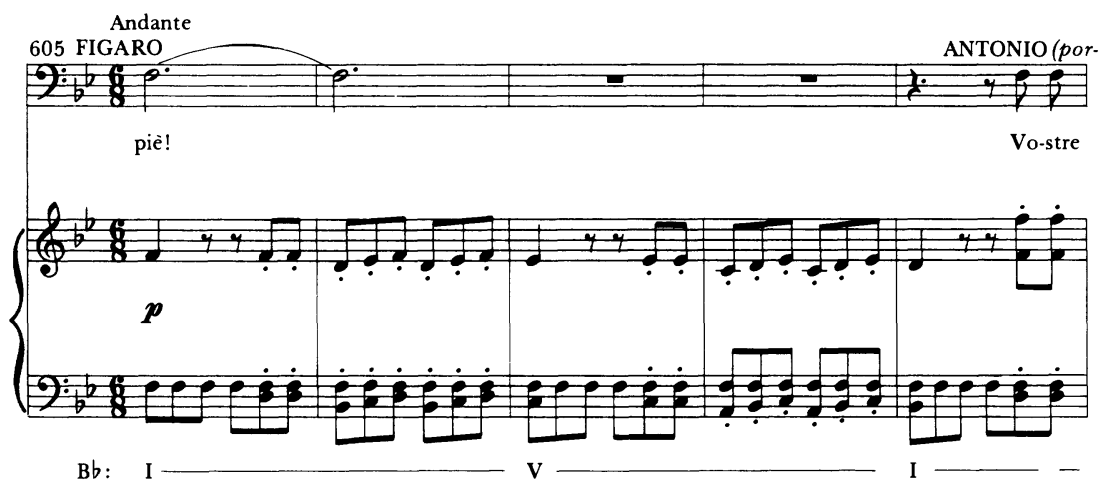

$610 \quad$ Il Conte (togliendogliele)

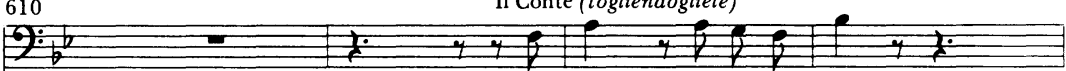

O- là, por-gi-le a me.
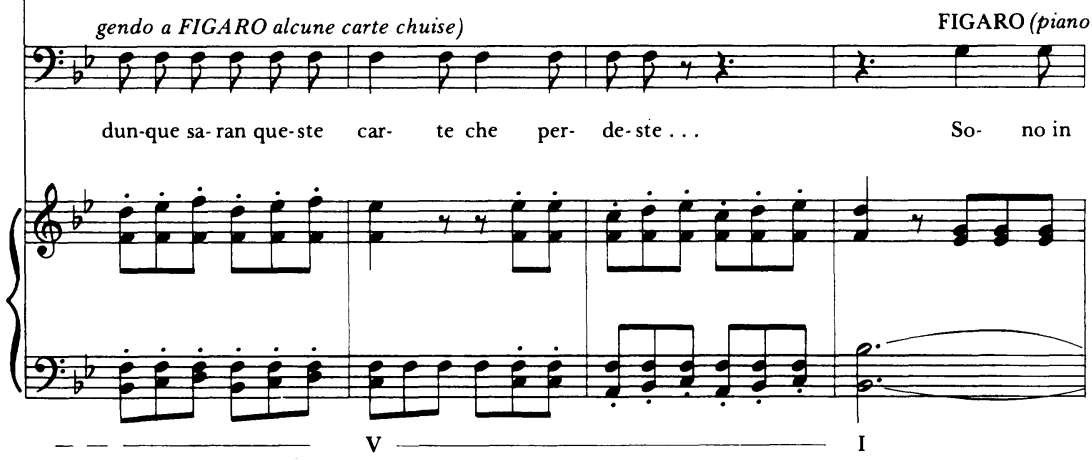

The reliance on repeated notes is quite clear (for example, in mm. 1923 and $38-45$ ), as are the syllabic singing and the succession of phrases that move to the downbeat on their last accented syllable. ${ }^{21}$

This excerpt also illustrates the way in which a through-composed active passage is organized at the level of the musical period. Its period structure is derived directly from the text of the passage, which is given

${ }^{21}$ Phrases like those ending in $\mathrm{mm} .23$ and 25 have two afterbeats rather than one, because some of the poetic lines are sdruccioli-they have two weak syllables after the last accented one. 
EX AM PLE 3. Rust and Mazzolà: Il marito indolente, Finale to Act I, section 6, mm. 17-57.
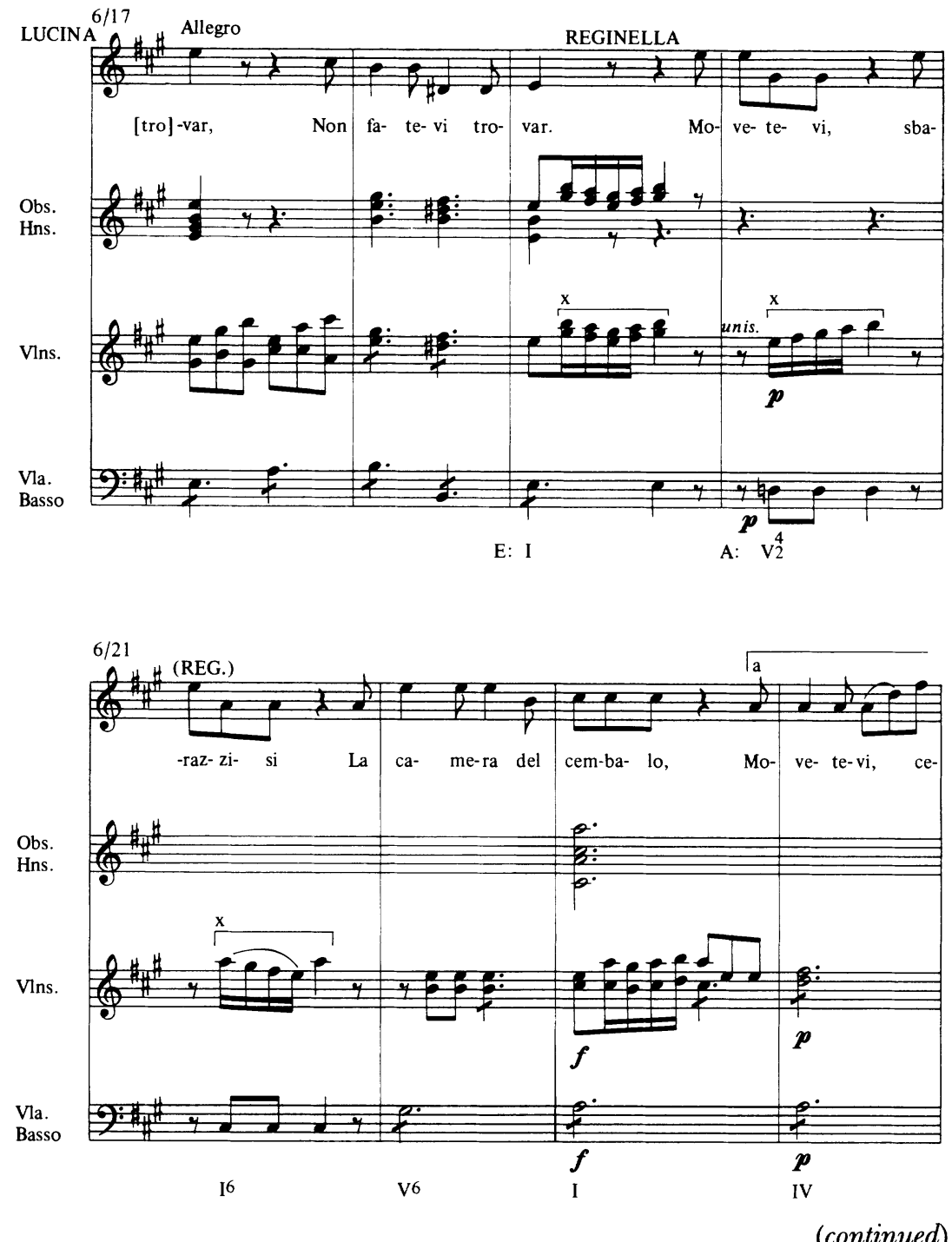

in Example 4. It begins with two successive quatrains, for Lucina and Reginella respectively. These are followed by a series of shorter speeches, and then a quatrain for Tranquillo. ${ }^{22}$ Each quatrain is set as a

${ }_{22}$ After the two initial quatrains is a change in poetic meter-quite rare in the middle of a scene-from settenari sdruccioli to ottonari. 
EX A M PE 3. (continued)
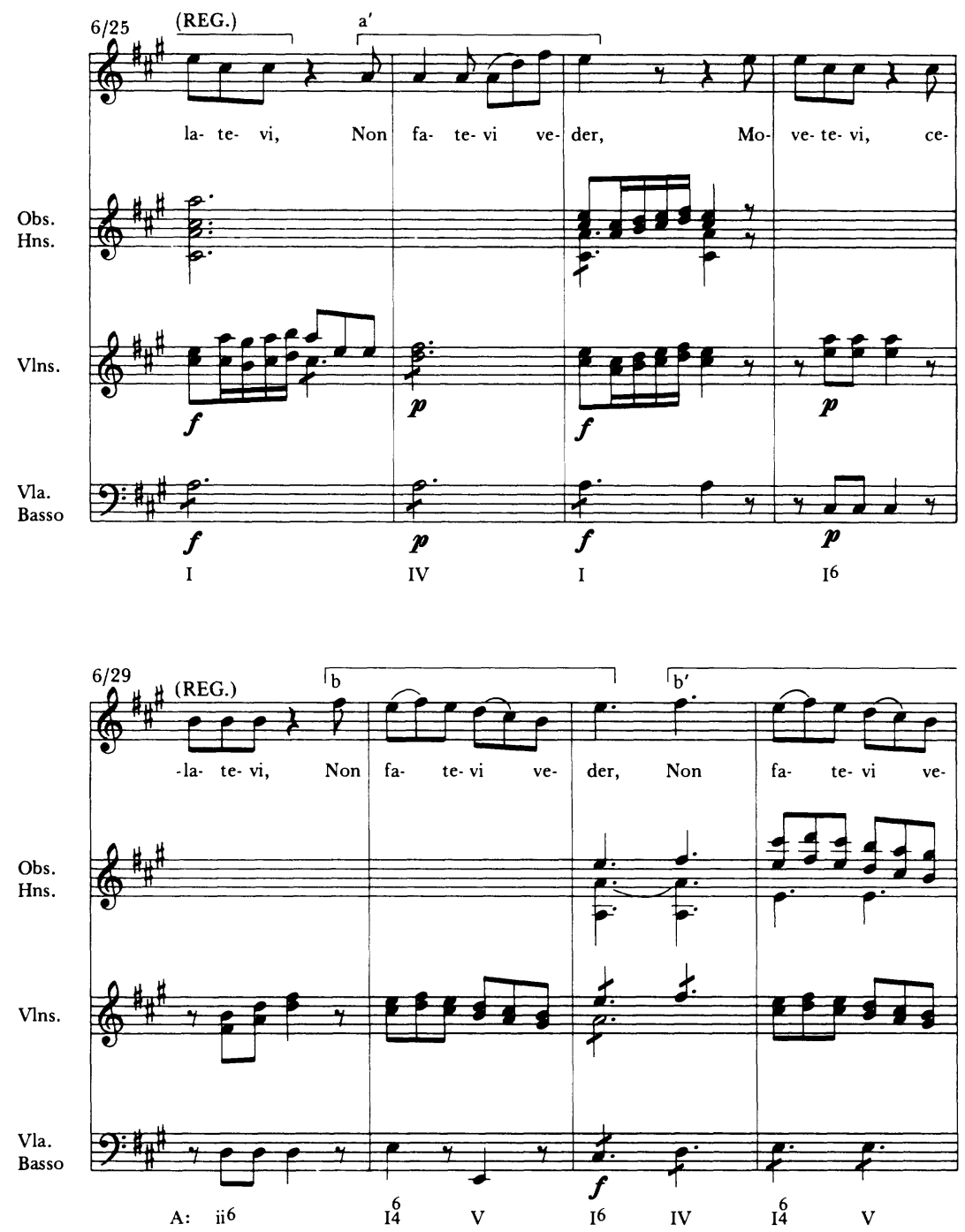

period concluding with a strong subdominant-dominant-tonic cadence; and the three full cadences at the end of the quatrains are the only full cadences in the passage. The shorter speeches between Reginella's quatrain and Tranquillo's are set more freely, and the last of them ends with a prominent half-cadence (in $\mathrm{m} .55$ ).

The setting of Reginella's quatrain (mm. 19-33) shows clear signs of 
EX A M P L E 3. (continued)
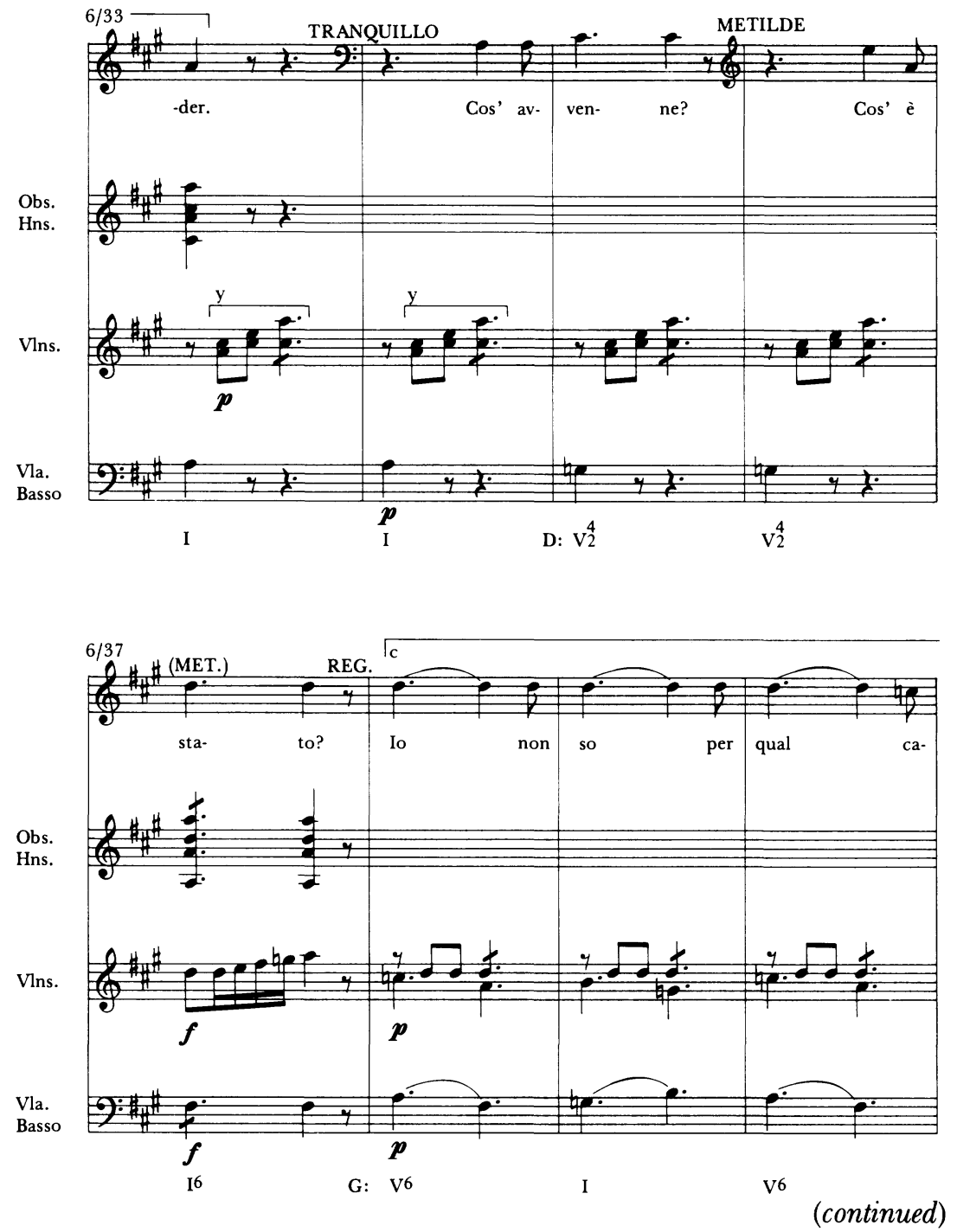

careful planning: it is in two parts, each of which moves from a declamatory beginning to more continuous phrases, and the point of greatest energy and continuity is reached in the closing phrases of the quatrain (mm. 3o-33). The first portion of the quatrain opens with two onemeasure phrases balanced by a two-measure phrase. The silent fifth beats in measures 20 and 21 break up these short phrases, which sound 
THE JOURNAL OF MUSICOLOGY

EX A M P LE 3. (continued)
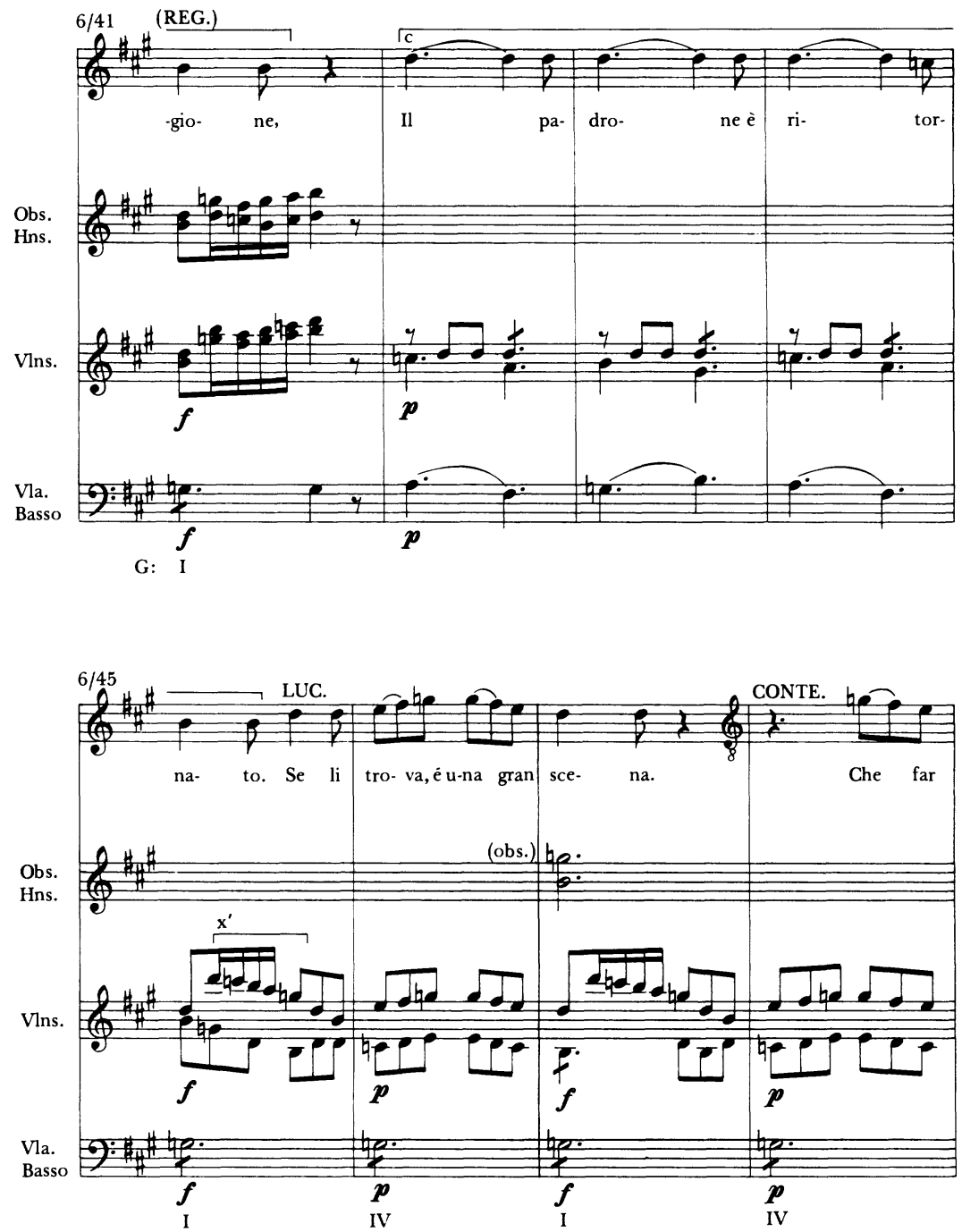

almost like accompanied recitative. The next two phrases (marked $a$ and $\left.a^{\prime}\right)$ are more lyrical and continuous, with an alternation pattern between IV and I in A, the new tonic. In the second part of the quatrain setting, "movetevi" and "celatevi" repeat (mm. 27-29), but here the harmonic progression $\mathrm{I}_{6}-\mathrm{ii}_{6}$ connects them with the following two-measure phrase (b) to drive towards the cadence. As often happens, the cadential pro- 
EXAMPLE 3. (continued)
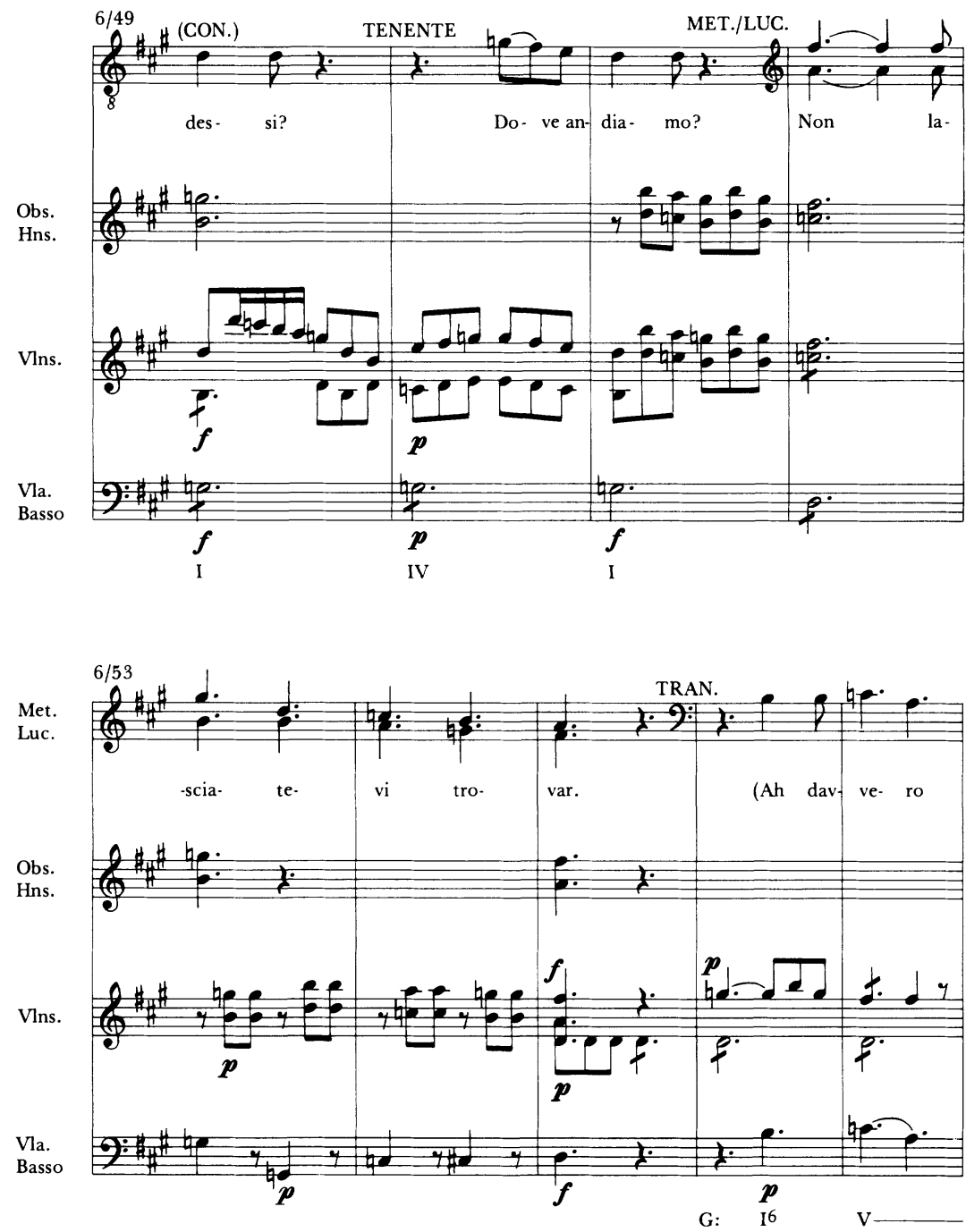

gression initially avoids closure (with the $I_{6}$ in $\mathrm{m} .3^{1}$ ), and then closes strongly when the phrase is repeated (in $\left.b^{\prime}\right) .{ }^{23}$

${ }^{23}$ A similar degree of organization is found in the other two quatrains. For the first 75 measures of the passage (through Tranquillo's quatrain), see Platoff, "Music and Drama," pp. $187-204$. 
EX A M PLE 4. Rust and Mazzolà: Il marito indolente, Finale to Act I, text from section 6 (part).

\author{
Lucina Fuggite-ohime! dal correre \\ La lena e il fiato mancami: \\ Andatevi a nascondere, \\ Non fatevi trovar. \\ Reginella Movetevi, sbarazzisi \\ La Camera del Cembalo, \\ Movetevi, celatevi, \\ Non fatevi veder. \\ Tranquillo Cos'avvenne? \\ Metilde \\ Reginella \\ Cos' è stato? \\ Io non so per qual cagione, \\ Il Padrone è ritornato. \\ Lucina Se li trova, è una gran scena. \\ Conte Che far dessi? \\ Tenente \\ Dove andiamo? \\ Lucina \& Metilde Non lasciatevi trovar. [al Con. e al Ten.] \\ Vi potete giù lanciar.
}

In contrast the following passage ( $\mathrm{mm} .33-55$ ), which sets the succession of short speeches leading up to the next quatrain, is much less tightly constructed. The phrases are of differing lengths, they are repeated a different number of times, and they follow one another without any clear plan. One or two lines of text could seemingly be added or removed without great difficulty. Most important, there is no sense prior to about measure 54 that the end of a musical paragraph is approaching, while in the quatrain setting just discussed cadential closure is signalled far earlier, and stressed by a phrase repetition. The carefully prepared cadence in measure 33 marked the end of a period; here the half cadence in measure 55 is more casual, and serves (with its prominent change of texture) to signal the beginning of the period that follows. This cadence, and more generally the structure of measures $33-55$, reveal the looser organization used for a succession of shorter speeches.

It is at the level of the period that signs of careful musical organization are most often to be found, within the otherwise throughcomposed active passages of the Viennese buffo finale. While the degree of organization varies, often in response to the structure of the text, 
the period is consistently the building-block. Apparently its use enabled composers to avoid structures based on returns of material at higher levels, and thus to emphasize dramatic continuity and the rapid forward motion of events, elements that are the key to the organization and the style of active passages.

Since expressive passages respond to very different dramatic and structural concerns, their musical settings are different in style from those of active passages. As we have seen, expressive passages follow active ones and complete action-expression cycles; they present static emotional contemplations of the situation at a given moment. Expressive passages also have a consistent position in the musical organization of the finale: as Table 1 shows, they normally conclude musical sections.

Not surprisingly, the music of expressive passages emphasizes stability and closure. This emphasis is reflected by their large number of cadential phrases, often repeated, and by a harmonic motion slower and more decisive than that of active passages. Patterns of tonic-dominant alternation are used only sparingly; instead many phrases employ IV-VI or $\mathrm{ii}_{6}-\mathrm{V}-\mathrm{I}$ progressions, strengthening harmonic closure.

Expressive texts are frequently quite short (four to six lines, or even fewer), but their settings are usually more extended than those of active passages. Repetitions of words or complete lines are common, along with repeated musical phrases, and the vocal style is somewhat more melismatic. These features give expressive passages a greater sense of expansiveness, which seems appropriate to the depiction of emotions. While active passages are somewhat analogous to simple recitative, expressive passages are the analogues to arias: they not only present but portray in music the emotions called for by the words. ${ }^{24}$ The independent role played by the orchestra in many active passages is absent in expressive passages, where the vocal parts consistently dominate the texture and control the phrase organization. This may be because the "busyness" and the higher profile of independent orchestral patterns were felt to interfere with the expression of feelings by the singers.

Finally, expressive passages generally exhibit a greater musical richness than active ones. Their music is intrinsically more interesting-it

\footnotetext{
24 Just as the musical information is kept to a relative minimum in many active passages, so that audiences can attend to the information being conveyed by the text, in expressive passages the words-repeated over and over-require less attention and listeners can follow the more complex flow of the music. In finales, as in the balance between recitative and aria, there is an inverse relationship between the amount of musical information and the amount of textual information being communicated.
} 
draws more attention to itself. This arises from a variety of features: imitative vocal entries, for example, or adventurous harmonic progressions, or particularly lyrical melodic writing. The specific details may vary from one case to another, but-especially in the finales of lesser composers than Mozart-it is consistently the expressive passages that are musically more substantial.

In any given finale the expressive passages vary considerably in size and degree of complexity. One or two may be quite short, and even perfunctory-they mark the end of the preceding action and bring the section to a close, but without any sense of a distinctive or interesting emotional statement. ${ }^{25}$ The others, however, are relatively extended and elaborate, with more dramatic gestures to mark the division between the active and expressive passage.

In Example 5, from the finale to Act II of Dittersdorf and Brunati's Democrito corretto, a fairly lengthy expressive tutti is quite strongly articulated from the end of the preceding active passage. The four-line text is a conventional one in which all three characters are confused and agitated, and it is written so that they can share nearly identical words throughout. The end of the active passage, with the approach to a half 212 cadence, may be seen in measures $98-103$. The onset of the tutti is marked first by a thinning of the texture to repeated Fs, and then by the entrance of the full orchestra with the voices in measure 103-two highly conspicuous changes of texture. This spot is also articulated by a sudden change in harmonic rhythm from the relatively rapid chord changes of the active passage to an eleven-measure prolongation of the dominant, with a pair of five-measure phrases $(a)$ creating a chain of suspensions above the pedal $F$. The result is a strong sense of agitation, in great part owing to the tension between the static dominant pedal and the energy of the rapid surface rhythm and the suspension pattern.

What follows is typical of a relatively elaborate expressive passage, both in its use of a point of imitation and in its strong sense of cadential drive and harmonic direction. The pattern in measures $113-21$ is really mock-imitation: after employing a brief imitative idea built firmly on the tonic chord, the long cadential phrase continues in simple homophony. Its cadence (in m. 125) is emphasized by two further pairs of shorter but equally cadential-sounding phrases, of four and two measures respectively $(b$ and $c)$. The repeated use of progressions such as $\mathrm{ii}_{6}-\mathrm{V}$-I gives the end of the tutti a strong sense of tonal stability and finality, which is heightened by the closing orchestral flourish.

${ }^{25}$ Measures $420-28$ from the finale to Act I of Cosi fan tutte exemplify such a tutti. In general, though, Mozart's expressive tuttis are longer and more interesting. The expressive tuttis (mm. 110-36, 198-218, and $267-91)$ of the three successive scenes from the Act I finale of Cosi cited in note 12 display many of the same stylistic features as the Dittersdorf example discussed below. 
EXAMPLE 5. Dittersdorf and Brunati: Democrito corretto, Finale to Act II, section 4, mm. 98-140.
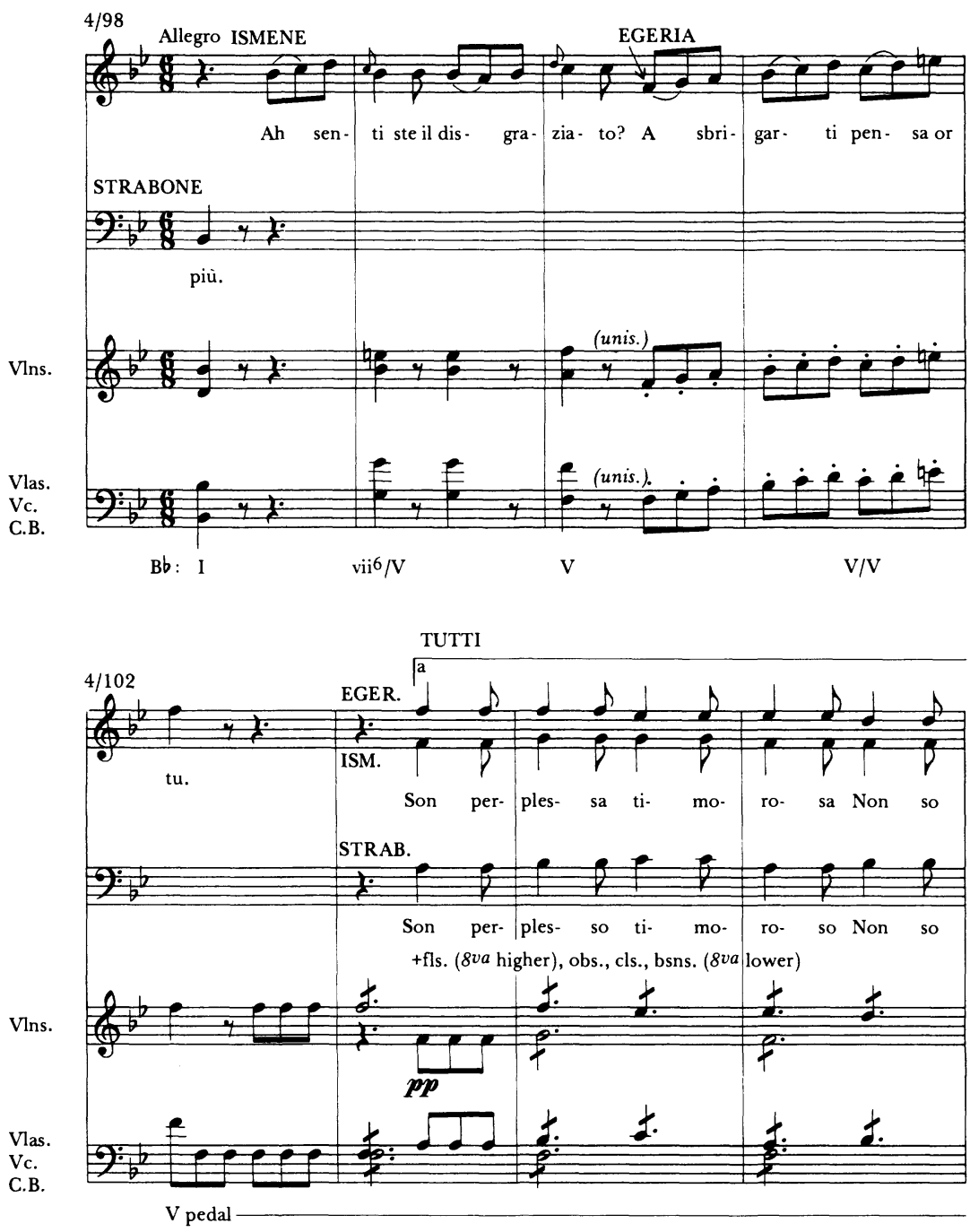

(continued)

Earlier in this essay I suggested that the organization of a buffo finale employed a standard model on which librettists and composers alike depended. The librettist provided a series of actionexpression cycles, each consisting of an active dialogue followed by an expressive tutti. The composer treated these cycles as units and set most 
EX AMPLE 5. (continued)
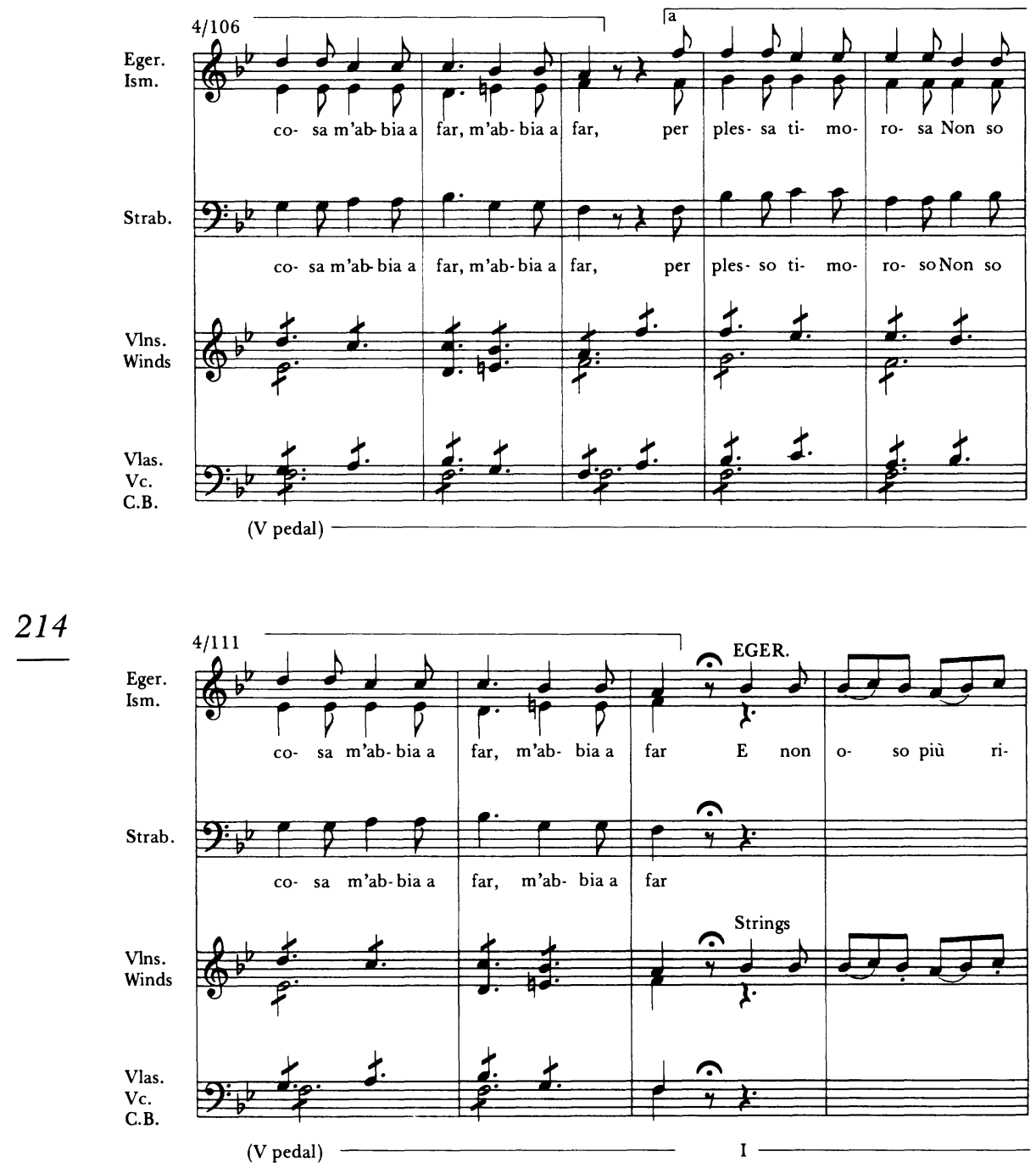

of them as discrete musical sections, with the end of the expressive passage and the end of the section coinciding.

We must now account for the expressive passages in a finale that do not follow the pattern outlined above. The procedures to be considered here are both exceptional and conventional-exceptional in that each of 
EXAMPLE 5. (continued)
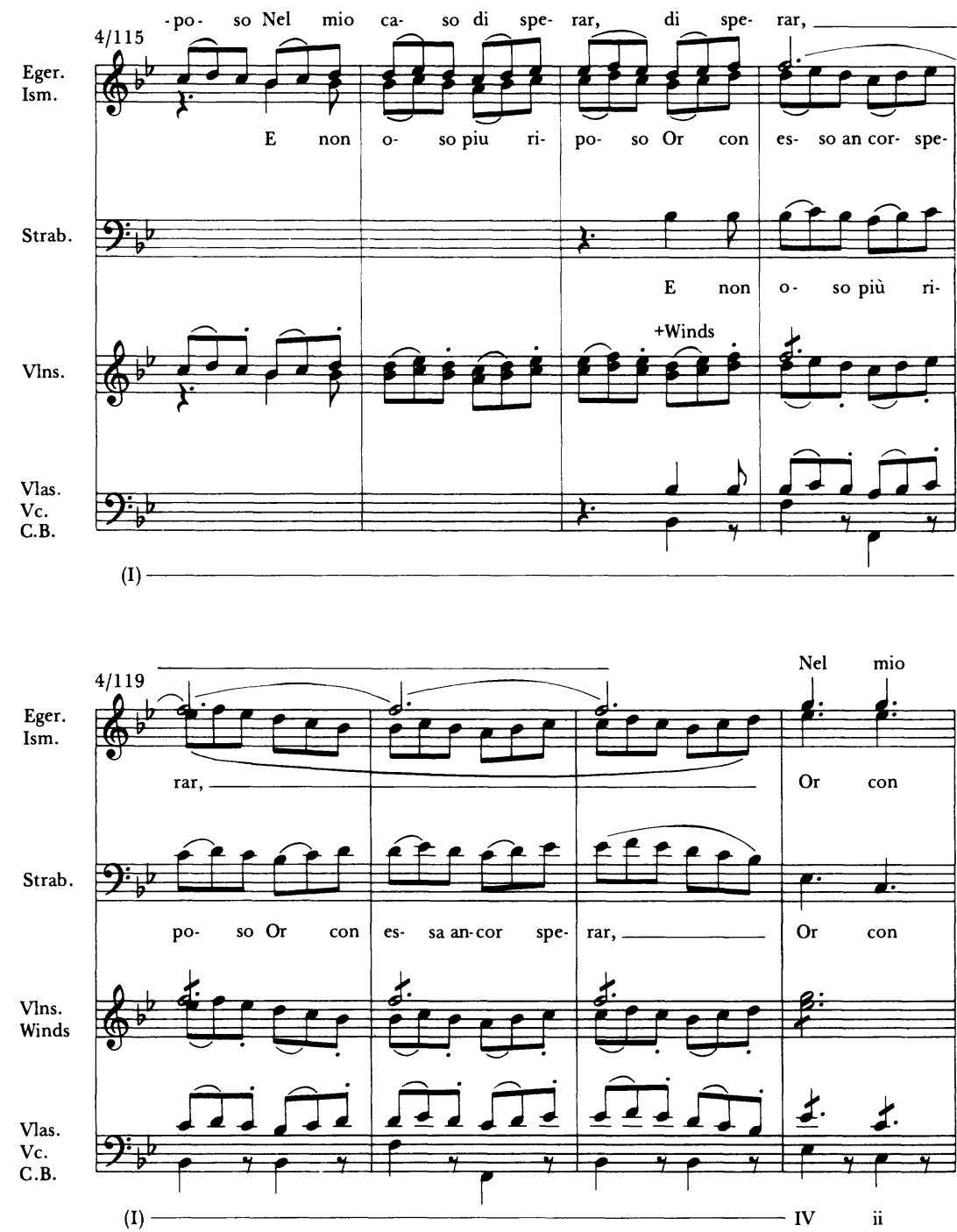

(continued)

them occurs only once or twice in a finale, but conventional in that all of them are found in almost every Viennese buffo finale of the 1780 os.

The first of these is the self-contained expressive passage, so-called because it is not linked to a preceding active passage but stands alone, either at the start of a finale or following a completed action-expression 
EXAMPLE 5. (continued)
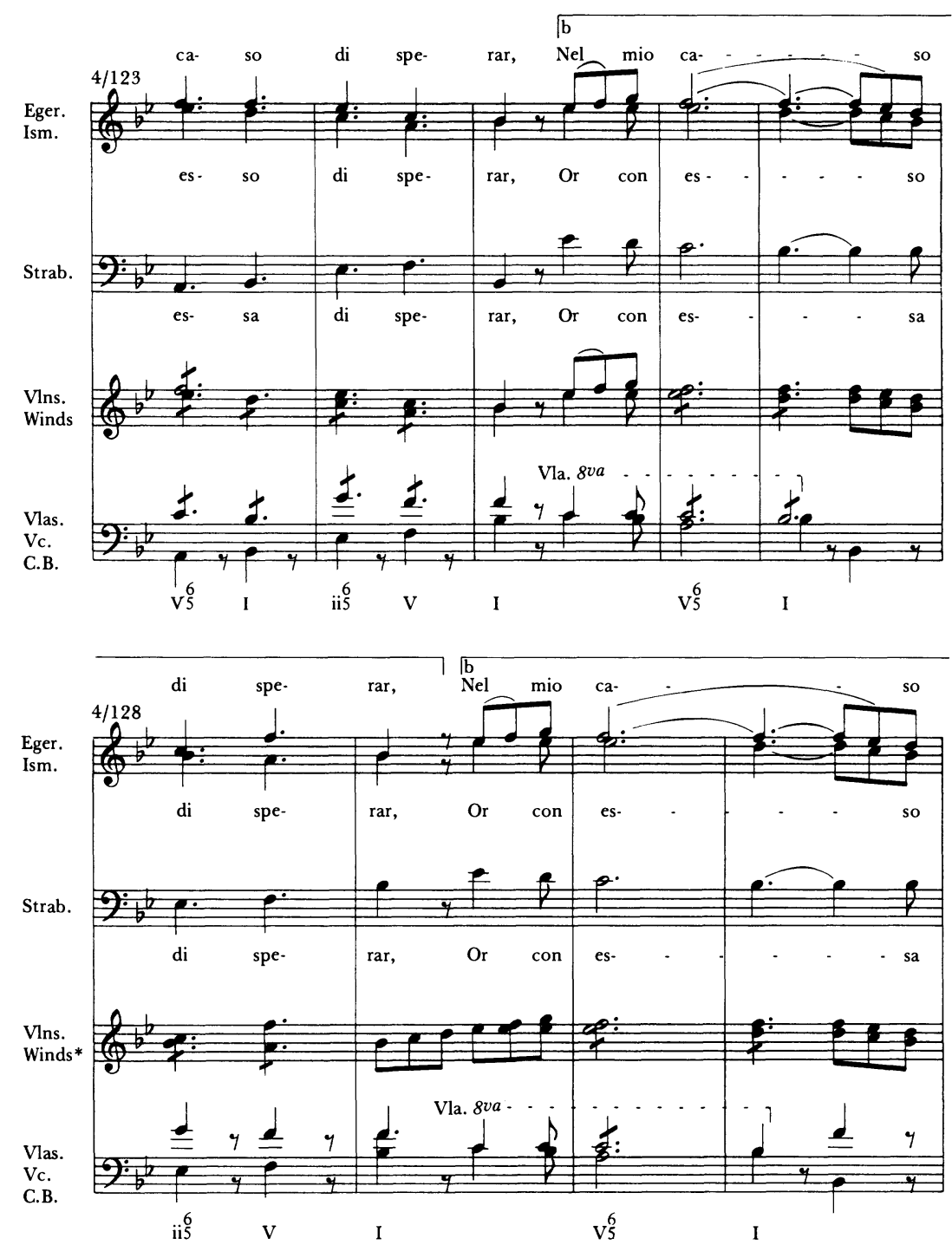

* Winds on beats 1 and 4

cycle. (See section 5 in Table 1.) Self-contained expressive passages serve as interludes in the dramatic progress of the story. Instead of making an expressive response to immediately preceding action, they convey more general feelings. The finale to Act I of Cosi fan tutte opens with a duet in which Fiordiligi and Dorabella lament the absence of their lovers, who 
EX A M PLE 5. (continued)
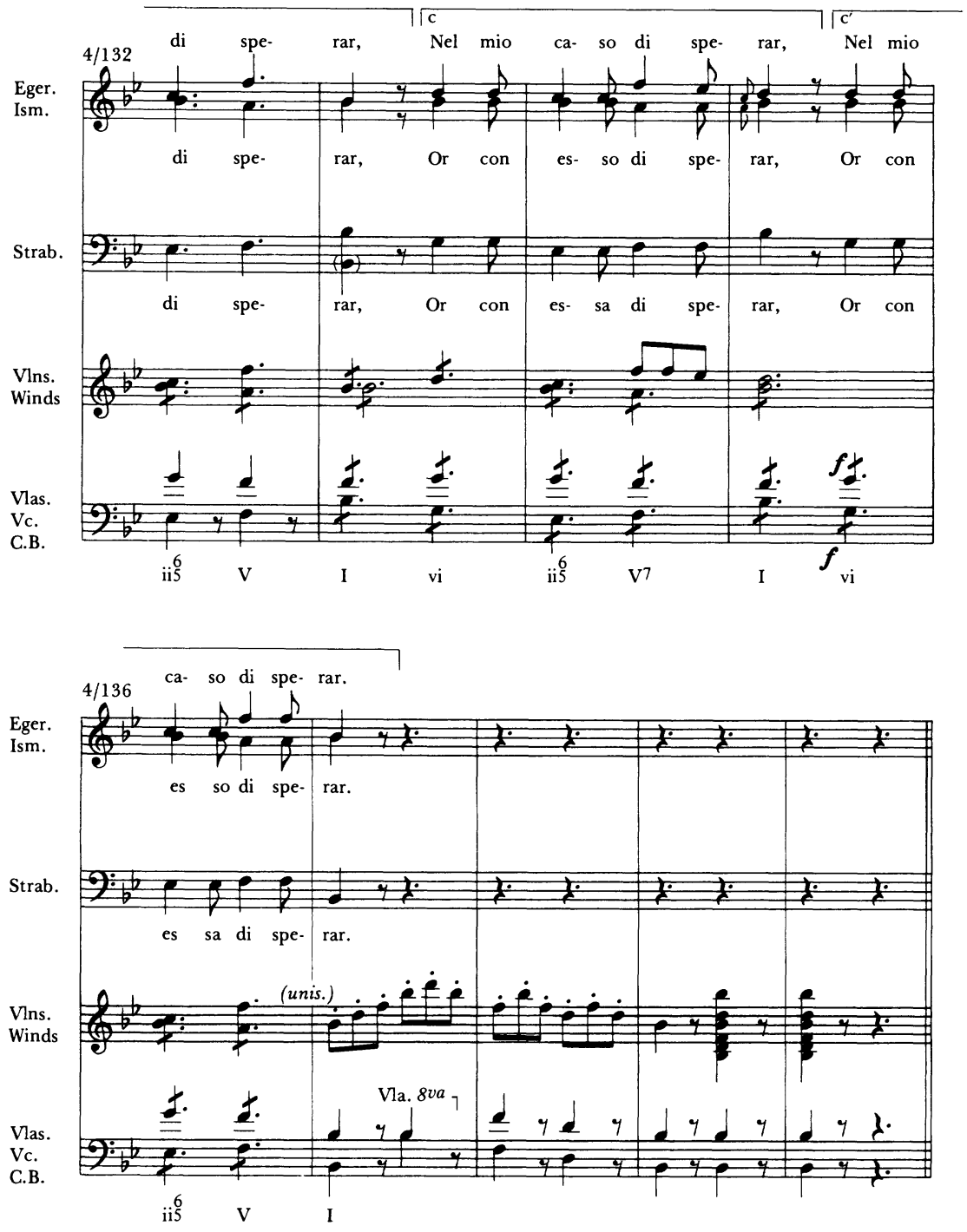

were supposedly called away on military duty earlier in the act. The philosopher Democrito, during the finale to Act I of Democrito corretto, expresses at length his scorn for the foibles of mankind: "We're all mad." His solo is less a response to specific events in the story than a comic statement about human behavior. And Angelica's solo, in the finale to 
Act I of Il burbero di buon cuore (Table 1), expresses her fears that she will not be able to marry the man she loves-fears that have tormented her throughout the first act.

What these examples have in common is their non-dramatic role. They are not undramatic, in the sense of dramatically ineffective; but they stand apart from the immediate situation. The duet from Cosi and the solo from Democrito, for instance, could have been put in a variety of other places in their respective operas without any harm to the dramatic flow; and Angelica's solo is if anything a dramatic redundancy, provided to give the prima donna another short aria.

Within a buffo finale, considerations of dramatic pace normally prevented composers from developing extended and strongly characterized expressions of feeling, especially more lyrical ones. But the dramatically "separate" status of self-contained expressive passages removes this restriction, so that expressions of calmer, less agitated emotions-which would have to be kept quite brief elsewhere in a finale-can be presented at some length. It is no coincidence that many of these passages are about love. For it is in self-contained expressive passages that composers can write in a style appropriate to feelings of love-a style which is incompatible with the agitated forward motion of the rest of a finale.

Many self-contained expressive passages are solos, set to music that is gentle, relaxed in tempo, and full of conjunct and sometimes florid melody. Such solos are often in closed forms such as $\mathrm{ABA}$ or $\mathrm{ABA}^{\prime}$, and they resemble arias in almost every respect, differing only by virtue of their somewhat smaller size. ${ }^{26}$ The lyrical style also characterizes most self-contained expressive passages for two or three singers. ${ }^{27}$ In fact, the only exceptions to the prevailing lyricism of self-contained passages are the occasional solos for comic characters, which adopt instead the style of the buffo aria. The broad humor of Democrito's solo from Democrito corretto depends principally on its mock-grandiose character, created by pompous dotted rhythms and occasional fortissimo interjections of the whole orchestra. Like the lyric expressions of love, this comic style represents an avenue of characterization best suited to non-dramatic interludes in a finale, when the demands of pace do not preclude the leisure and expansiveness necessary to make such a characterization successful.

At the most dramatic points of a finale composers employed an-

${ }^{26}$ As stated earlier, most movements in buffo finales are through-composed. Selfcontained expressive passages and strette (to be discussed below) are the only movements in which large repeats of material regularly occur.

27 An example by Mozart, in addition to the duet for Fiordiligi and Dorabella from Cosi, is the famous trio for Donna Anna, Donna Elvira and Don Ottavio in the Act I finale of Don Giovanni, "Protegga il giusto cielo" (mm. 251-72), with its strikingly lyrical and florid melodic writing. 
other exceptional, if conventional, procedure: they purposely detached an expressive tutti from its preceding active passage and set the tutti as a separate movement. The change of tempo, meter, or both between the active and expressive passages highlights the latter as a separate entity. As a result the expressive reaction to the events of the plot is less integrated into the ongoing action and perceived more as an event in its own right.

In the Viennese buffo finales of the 178 os "detached" expressive tuttis occur in one of two dramatic situations. Either the tutti is an astonished response to some unexpected event in the story-what I will call the shock tutti-or it is the final expressive passage of the act, the stretta. Each of these types has its own characteristic musical style.

Many buffo finales are constructed so that their action builds towards an unexpected turn of events, a twist of the plot that takes the characters, if not the audience, by surprise. At this point librettists wrote a tutti in which the characters express their shock, and composers treated this passage in a special fashion. ${ }^{28}$ This is precisely what has happened in sections 9 and 10 of the finale to Act I of Il burbero (see Table 1): the shock tutti (section 10) has been split off from its preceding active passage and set as a separate movement.

The essential quality of a shock tutti is its sense of separateness from the ongoing, generally rapid and continuous activity of the rest of a finale. Here the normal pace and flavor of the finale temporarily disappear-the rules are momentarily suspended. But unlike selfcontained expressive passages, which stand aside from the action of the finale, shock tuttis interrupt the action, bringing it to an enforced halt at a highly dramatic point. They thereby increase the dramatic tension, which must be released in the loud clamor at the end of the finale.

In the finale to Act I of Il marito indolente, the shock tutti occurs at the climax of a typically silly situation. When Fulgenzio returns to his house, where a party he has forbidden is going on nonetheless, two of the party-goers jump out at him wearing frightening masks, making loud noises and stamping their feet. The ensuing shock tutti expresses Fulgenzio's fear of the "spirits" and the guests' fear of Fulgenzio's anger (see Example 6).

${ }_{28}$ The shock tutti seems not to have been commented upon by writers on 18 th-century opera buffa, perhaps because the examples in the finales of Mozart are not particularly clear. But both Gossett, " 'Candeur virginale'," p. 327 , and Julian Budden, The Operas of Verdi, 3 vols., I (New York, 1973), 18-19, discuss the equivalent movement-usually called the andante or the largo concertato-in operatic finales of the early 19 th century. In Budden's words, "here everyone is 'struck all of a heap', as the result of some unexpected revelation. The dramatic development comes abruptly to a halt, as all express their utter astonishment, sometimes in a false canon, as in the Barber [of Seville, by Rossini]; sometimes in an elaborate unaccompanied ensemble as in [Rossini's] Le Comte Ory.' 
EX AMPLE 6. Rust and Mazzolà: Il marito indolente, Finale to Act I, section 8, mm. 1-17.

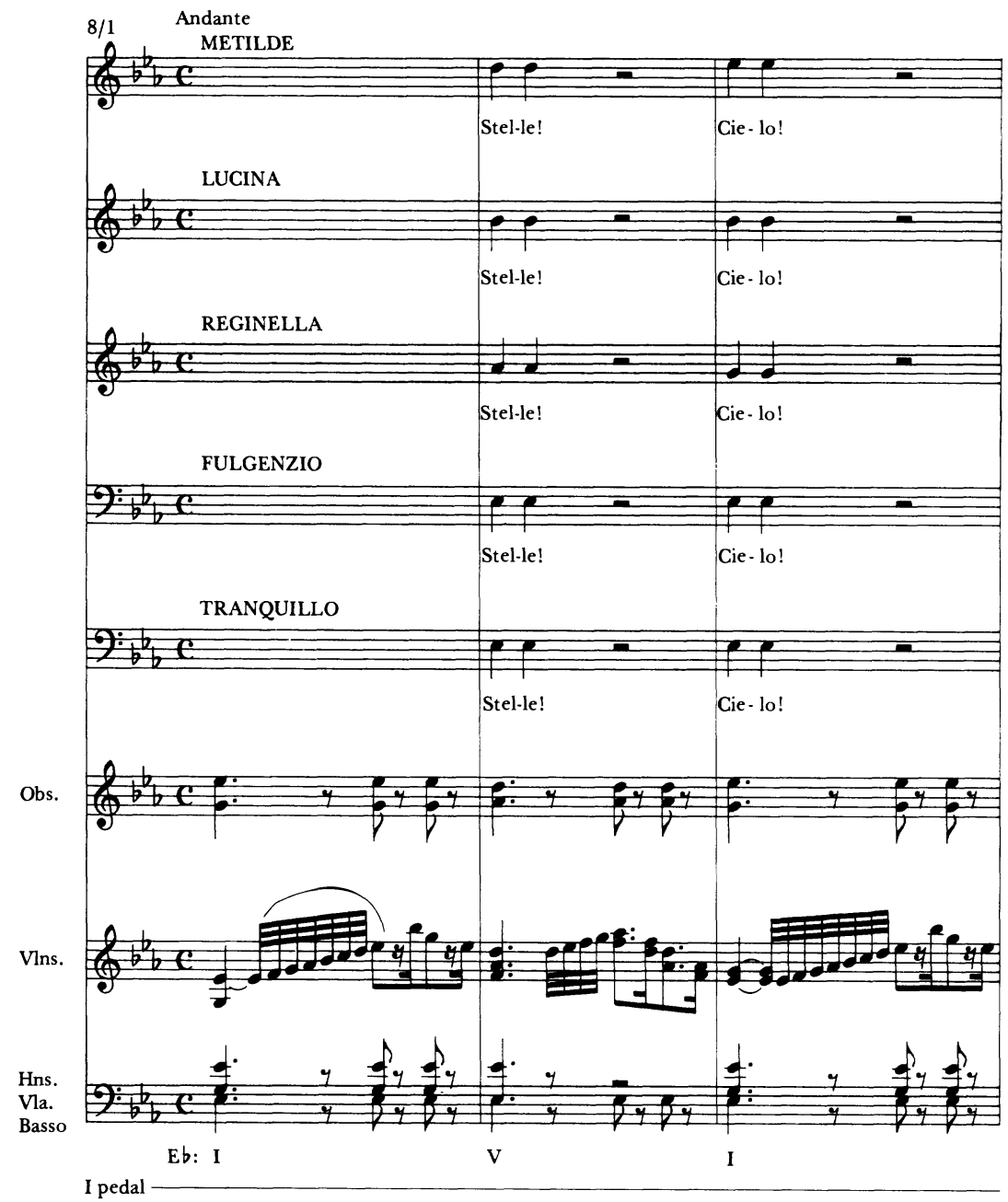

The key feature of this and other shock tuttis is that everything stops-time is momentarily frozen. Naturally the slow tempo is a contributing factor, but other elements are important as well. In measures 1-5 the hesitant declamation, with lines split into short exclamations, conveys the difficulty the characters have in expressing their astonishment. The effect of choppiness is also suggested by the dotted rhythms and rapid grace-notes in the violins in measures $1-4$, which call for a 
EX A M PLE 6. (continued)

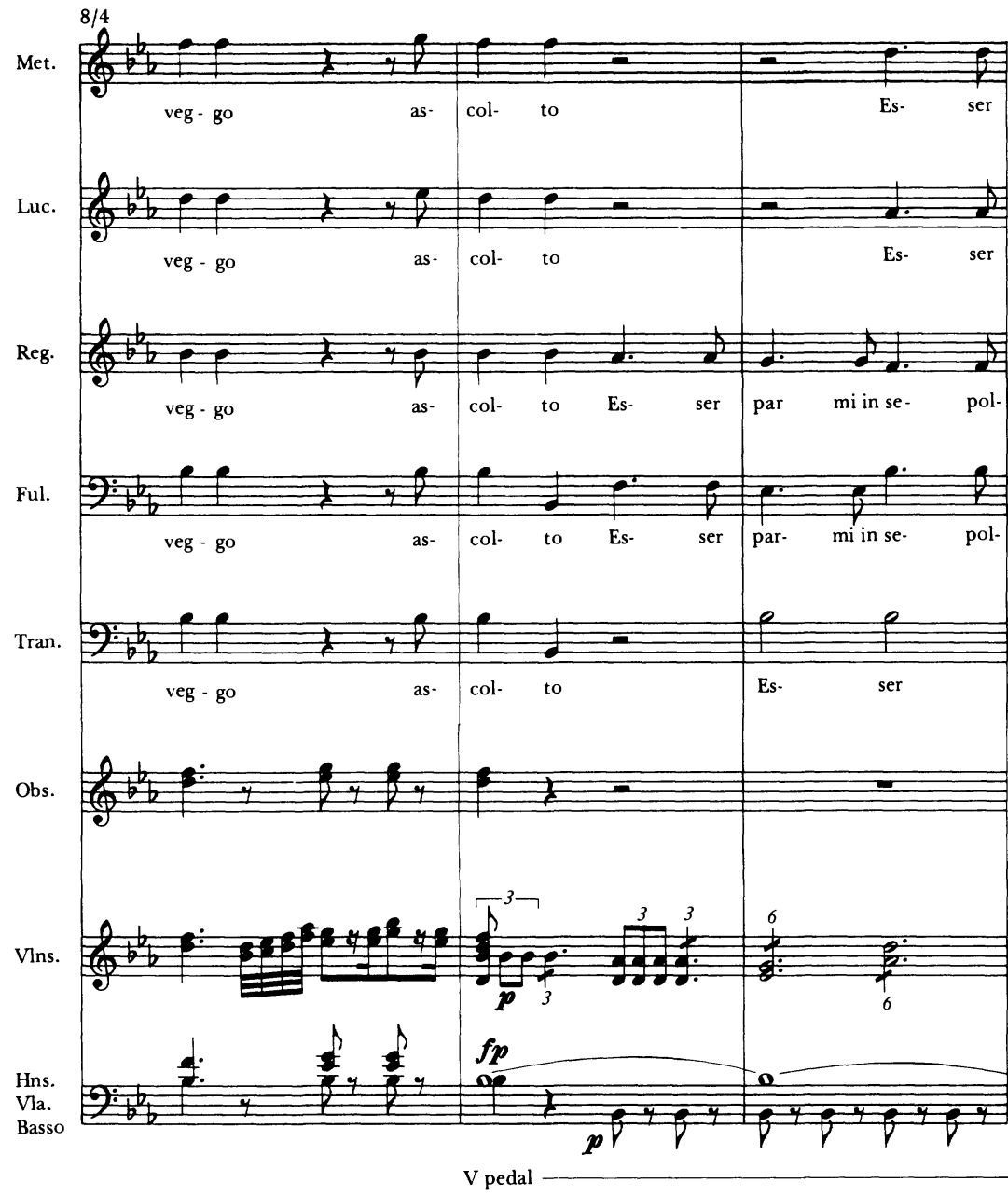

(continued)

marcato style. Harmonic stasis is created by the I-V-I alternation above a tonic pedal in the first three measures; this pattern (or, alternatively, Ivii-I above a tonic pedal) occurs very frequently in shock tuttis. Pedals elsewhere in the example minimize the sense of harmonic motion, along with a slow harmonic rhythm: only in measures 13 and 16 are there more than two chords per measure. A soft dynamic level, here implied at times by the dynamic markings in the orchestra, is often explicitly 


\section{EXAMPLE 6. (continued)}

Met.

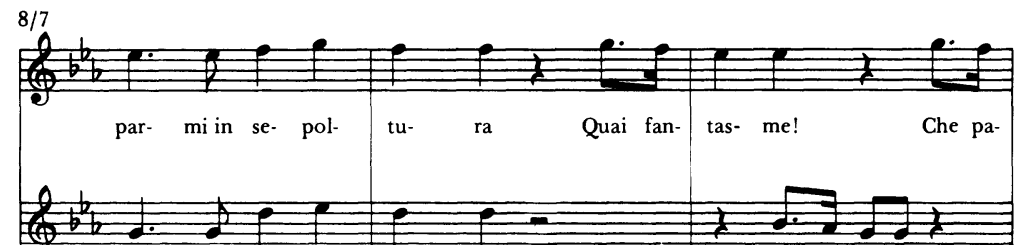

Reg.

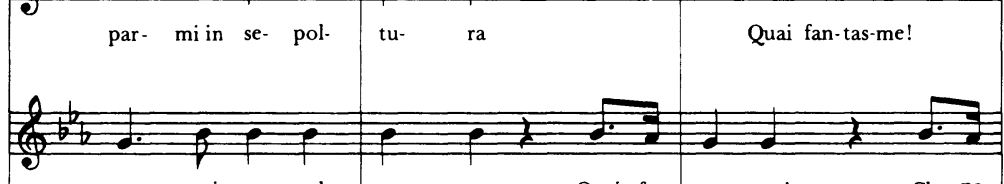

Ful

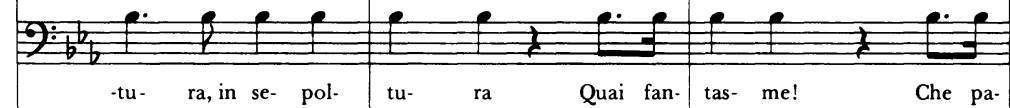

Tran.
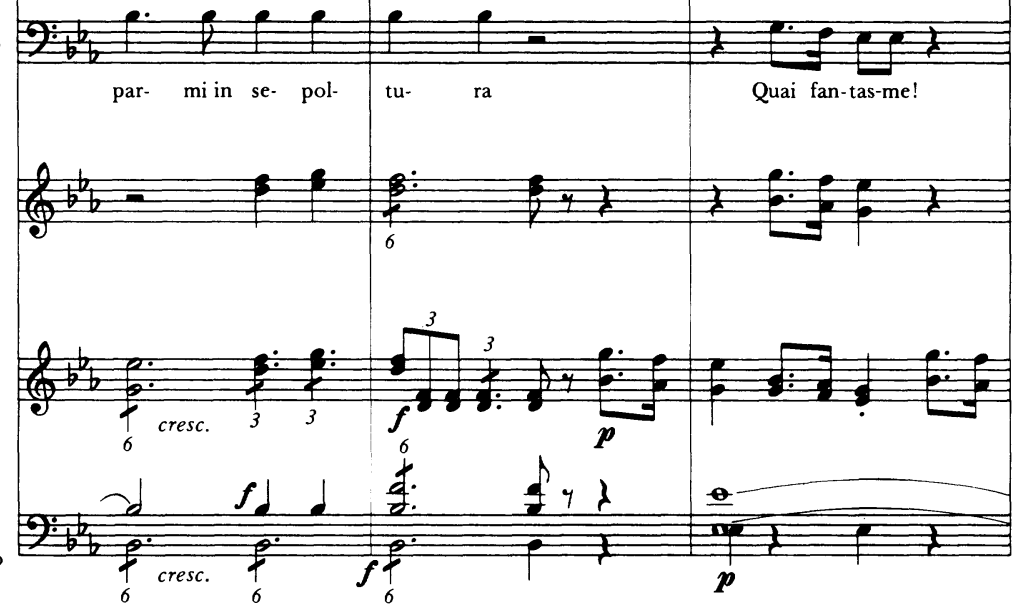

called for by the words "sotto voce" in the vocal parts. In fact, the quiet parts of a shock tutti are nearly always the quietest points in the finale. ${ }^{29}$

29 The best-known shock tutti in the opera buffa of the 18 th century is undoubtedly the moment in the finale to Act II of Figaro when Susanna emerges from the closet to the confusion of the Count and Countess, who both expected to see Cherubino. This example, however, is more complex in several respects than the typical shock tutti. For a detailed discussion, see Platoff, "Music and Drama," pp. 69-71 and 3o6-1 2. 
EX A M P E 6. (continued)

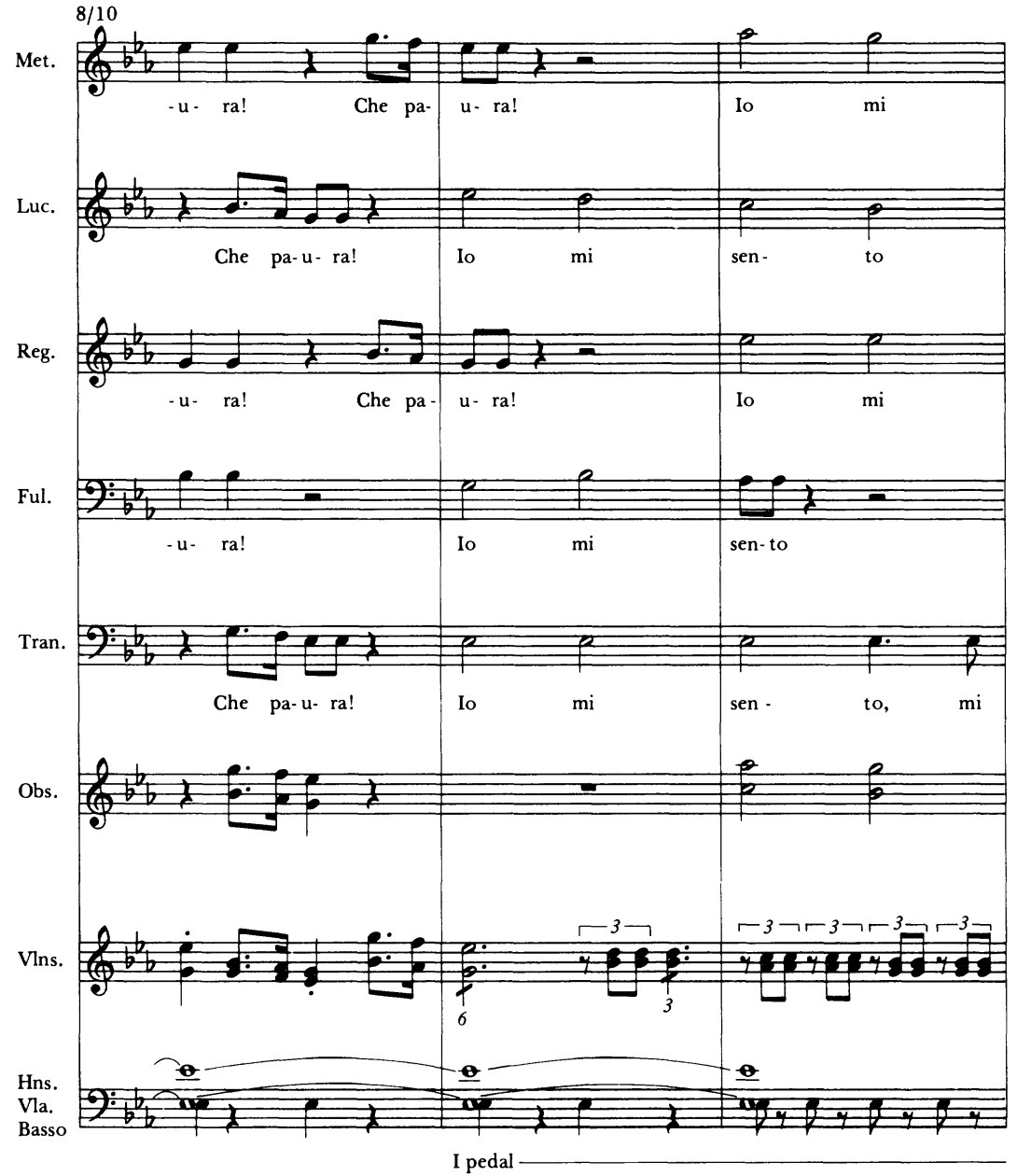

(continued)

While the shock tutti marks a moment when the agitation of the finale freezes in surprise, the stretta does the opposite: it brings that agitation to its boiling point. The stretta is also the spot in a finale where dramatic values most clearly give way to musical ones. All finales escalate an already existing dramatic conflict into a crisis. The last stages of this escalation invariably comprise two steps: an argument or other free-for- 
EXAMPLE 6. (continued)

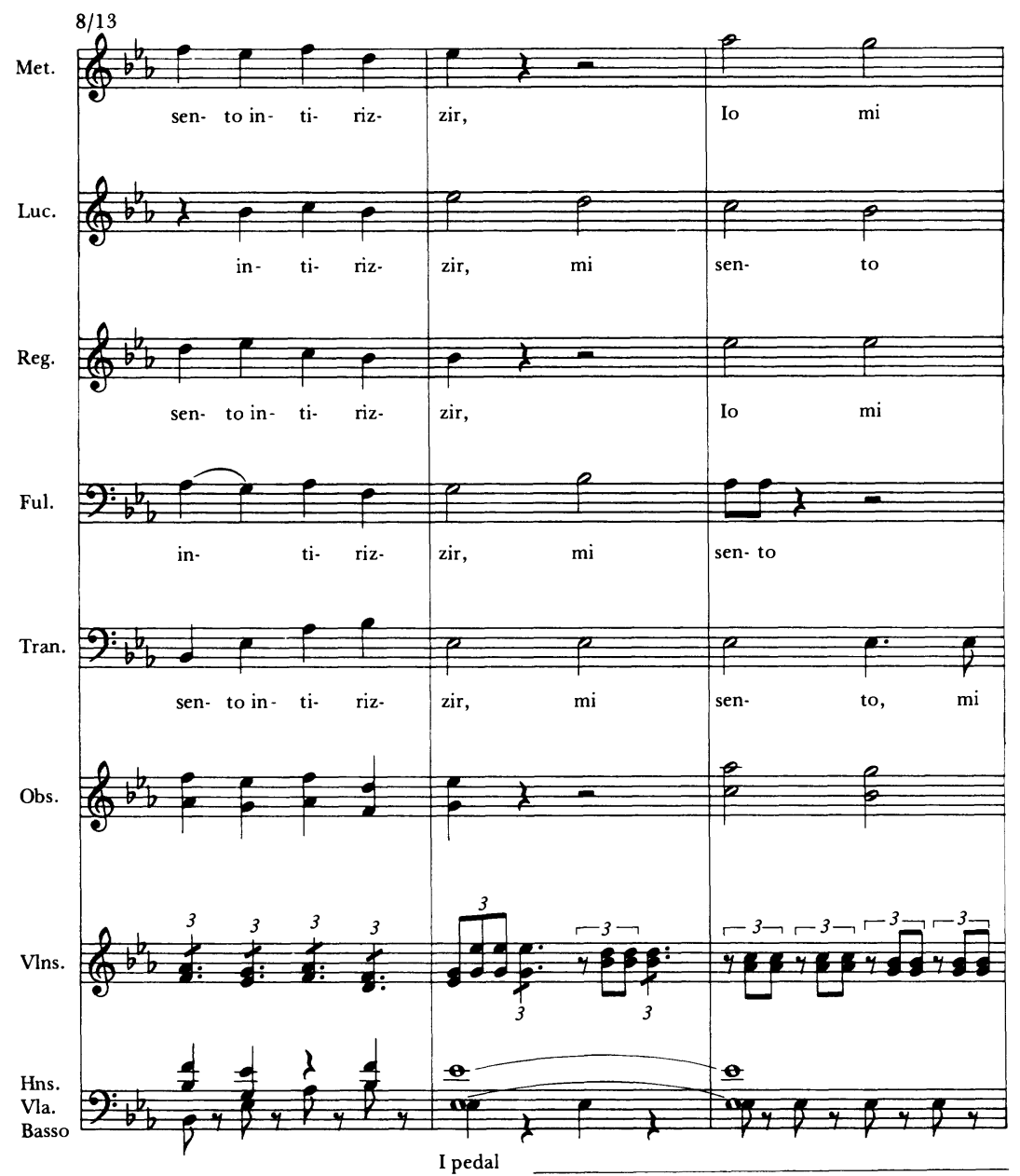

all conversation among all the characters, and a concluding tutti. $3^{\circ}$ Depending on the nature of the story, the tutti may present either a unanimous expression of feelings by all the characters (fear of a sudden thunderstorm, for example) or a conflict between two opposed groups of characters. The latter approach was generally preferred by Da Ponte, as in the first finales of all three of his librettos for Mozart. Clearly it of-

3o Because the last finale of an opera depicts the happy resolution of the plot rather than the height of its conflict, the stretta in the last finale is normally more harmonious, and often somewhat shorter, than those found in earlier acts. But in most other respects it resembles the typical stretta as discussed below. 
EX A M PLE 6. (continued)

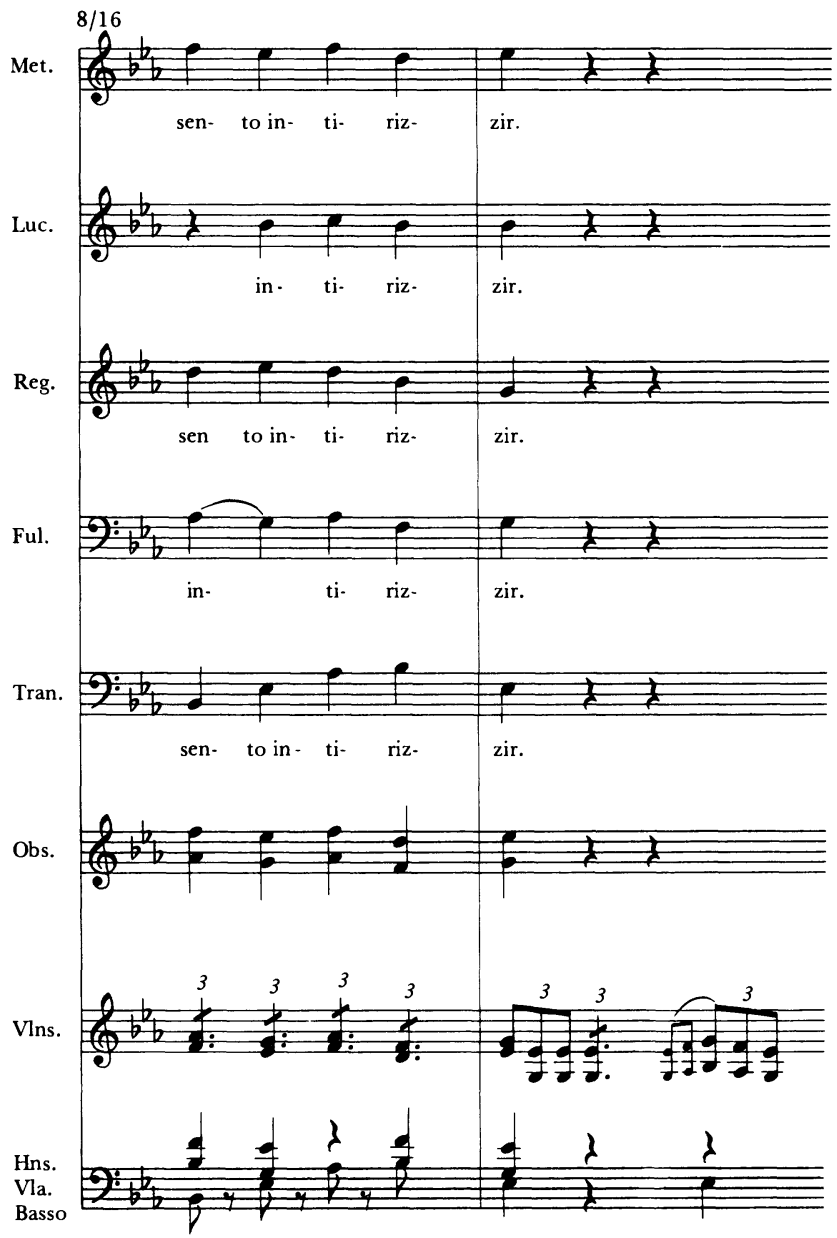

fers both a dramatic advantage - a vociferous argument is more interesting than unanimity, even a fearful unanimity - and a justification for the common technique of setting off groups of characters antiphonally against one another. ${ }^{31}$

31 In most finales the shock tutti and the stretta occur at different points in the finale, and each results from an action-expression cycle being split, with the expressive tutti set as a discrete movement. However, in the Act I finale of $I l$ burbero shown in Table 1 the shock tutti and the stretta occur in succession (sections 10 and 11 ), as reactions to the same action. For this reason-and untypically-there is no active passage to which the stretta is an immediate response. 
The stretta from Act I of Don Giovanni can serve to illustrate the most common features of such passages..$^{2}$ It is the largest section of the finale, comprising 121 measures, and this large size is achieved primarily through extensive repetitions of material. At lower levels, its various short phrases are nearly all immediately restated (as in mm. 548-54 and 623-39). And its overall structure relies on the common formula of several opening phrases, a central repeated passage, and a coda, producing an $\mathrm{ABBC}$ form (here the central repeated passage occurs in $\mathrm{mm}$. 55783 and $586-612)$.

The use of such a long repeated section, which states over and over words that do not need repeating, suggests that, in the stretta, dramatic values are by convention subordinated to musical ones. 33 In view of the limited amount of dramatic information that this part of a finale generally conveys - it is all loud argument and agitated emotions-the shifting of the balance towards the musical side can occur without doing violence to the drama. To consider the matter from another angle, finale texts are devised so that by the start of the stretta, the important action has concluded, and pure musical excitement can take over.

The musical elements of the Don Giovanni stretta all serve its basic 226 purpose - to bring the conflict to a highpoint and to earn the composer applause. It depends on passages that build in energy and intensity, and particularly on various sorts of crescendo patterns, such as the phrase over a tonic pedal in measures 537-41. These passages are usually decisive cadential phrases, which may be repeated at great length. Much of the vocal writing is in pure homophony, relying on an effective contrast between declamation in long notes and rapid patter. The conflict between Don Giovanni and Leporello and the other characters is played out in a variety of antiphonal arrangements, sometimes featuring long notes for the larger group and faster singing for the two men (see mm. 569-73). Frequently the rhythmically enlivened antiphonal singing gives way at the end of a phrase to a strong cadence sung homophonically (mm. 623-31). Everything contributes to a sense of rising excitement, including the use of the long repeated passage. This passage moves from a low level of energy, intensity and dynamics to a high

\footnotetext{
$3^{2}$ I have chosen this example partly because scores are readily accessible; but it is also worth noting that Mozart's operatic writing is least different from that of his contemporaries in the more conventionalized parts of finales, of which the stretta is certainly the clearest case.

${ }_{33}$ This is even clearer in cases when, as in the finale to Act I of Cosi fan tutte, a composer set as the final stretta not just the last expressive tutti, but the preceding active passage as well. It results in a striking lapse of dramatic realism-admittedly not a high priority in 18 th-century opera generally - since the extended repetition of music normally includes the active passage as well as the tutti. Such a repetition creates a dramatic redundancy: the final argument leads to the expressive reaction, but then the argument (and the reaction) returns.
} 
point; when it can climb no further, the music drops back to piano and begins again. 34

While the rapid motion and energy of the stretta may suggest a similarity to active passages, in most respects its style represents a marked change from their unobtrusiveness and continuity. The excitement in an active passage derives chiefly from the rapid advance of the dramatic action, usually supported by a skillfully patterned musical accompaniment that maintains a sense of forward motion. But in a stretta, with its repeated buildups of intensity and its frequent changes of declamation and vocal texture, the excitement is entirely musical; it is, paradoxically, a point both at which dramatic time stops and in which the emotional energy of the drama is expressed most forcefully. The musical emphasis is not on continuity but on its opposite: strongly articulated points of closure, which build steadily towards a climactic cadence. A large part of the excitement of a stretta arises from the fact that it calls the audience's attention so forcefully to the impending end of the act-listeners are exhorted to get in on the fun, because it is about to end. In this respect the stretta is like the coda of an instrumental work, which generates its emotional power (excitement, pathos, resignation) in part from its clearly understood position as the final statement of a movement.

The different types of expressive passage outlined above provided composers with a means to control dramatic pace within a finale. Dramatic pace-the rate at which the plot is perceived to advance-depends fundamentally on the treatment of the expressive passages and the handling of articulations between sections. A finale presents a series of plot events alternating with pauses. The more each expressive pause is emphasized, the stronger will be the sense that the story is temporarily not advancing, and the more time there will seem to be between one action and the next.

In most cases, as we have seen, active passages lead directly into expressive passages without a break in the musical continuity. It is true that a change in vocal texture from solo to ensemble singing occurs, and certain gestures such as dominant pedals also mark the start of expressive passages. But because the tempo and meter of the section remain unchanged, relatively little attention is drawn to the expressive passage as a separate entity. On the other hand, expressive passages all conclude

34 This example lacks one feature common to most strette: a long, gradual "Mannheim" crescendo over a tonic pedal, with instruments and voices added a bit at a time. Among the many instances of this practice in the 1780 , the most celebrated at the time (and justly so) was the finale to Act I of Paisiello and Casti's Il re Teodoro in Venezia. 
with articulations, followed almost always by a new active passage. The dramatic pace seems rapid, since nearly every time the attention of listeners is attracted by the start of a section in a new tempo and meter, they hear an active dialogue. (This may be seen in Table 1.) The fast tempo of most active passages and their emphasis on continuity only strengthen the perception of rapid dramatic motion.

Without any highly articulated moments of contemplation or expressive reaction, a finale would seem to present a continuous flow of dramatic activity. These moments are provided by the self-contained passage, the shock tutti, and the stretta. Each is an expressive passage that begins a new musical section, thus calling greater attention to itself. Self-contained passages bring a moment of relief from the dramatic haste of the finale; they stand aside from the bustle, rather than interrupting it. The shock tutti, on the other hand, brings the finale to a sudden halt at a tense dramatic moment, and its slow and quiet hesitancy heightens the tension by delaying its resolution. At the end of the finale, the climactic musical excitement of the stretta releases this tension in a satisfyingly noisy fashion. It is in these passages that the otherwise uniformly rapid dramatic pace of the finale is altered, and listeners focus most consciously on emotional responses.

This study of the Viennese buffo finale has proceeded from the belief that the operatic works of Mozart need to be viewed in the light of the practice of his contemporaries, so that we may better understand the combination of the conventional and the innovative in Mozart's operas. It is clear that a number of important musical and dramatic conventions, hitherto largely undiscussed, shape the buffo finale of this period. An awareness of these conventions and how they operate is a necessary prerequisite to an improved understanding of what a buffo finale is, and what distinguishes a typical example from an unusual or daring one. 35

The basic organizing principles of the finale stem from the dramatic and poetic structure of the libretto. The consistent segregation of active dialogues from expressive tuttis and the various points of articulation in the text were the focal points on which the composer relied in determining the overall shape and expressive nature of the music. Both the musical styles of individual sections and the points of articulation between sections were dictated in large part by convention, following predictably from the organization of the text. And the handling of active and expressive passages in a finale gave composers a tool with which to control its dramatic pace. 
Finally, the degree to which the organizing forces for the buffo finale are dramatic and textual, rather than "purely musical," suggests a fruitful direction for further study of other elements of the opera buffa in this period. One avenue to a deeper understanding of the opera buffa as a whole-its arias, recitatives, ensembles, and larger organizationwill surely be a closer study of the libretto and its dramatic implications and directives, coupled with a readiness to discard as inappropriate many of our preconceptions, derived from instrumental music, about how musical works are structured.

Trinity College, Hartford, Conn.

${ }_{35}$ While it is not possible within the scope of this paper to offer a detailed comparison between Mozart's finales and those of his contemporaries, the dependence of Mozart's buffo finales on the structural characteristics discussed here should already be quite clear. Notwithstanding the oft-made assertions about the formal principles at work in Mozart's finales, his finales differ from those of other Viennese opera composers more in the areas of orchestration, harmonic interest, and textural complexity than in that of structural organization. 


\section{APPENDIX}

\section{Opere Buffe Premiered in Vienna \\ Between 1781 and January 1790}

Title of Opera

Il mercato di
Malmantile
Il re Teodoro in
Venezia
Il marito indolente
Il ricco d'un giorno
L'incontro inaspettato
Gli sposi malcontenti
La grotta di Trofonio
Il burbero di
buon cuore
Il finto cieco

\section{Le nozze di Figaro}

Il demogorgone

Una cosa rara

Gli equivoci

Democrito corretto

Il Bertoldo

L'arbore di Diana

Il talismano

Il pazzo per forza

Il pastor fido

La cifra

Cosi fan tutte
Date

26/i/1784

23/viii/1784

$25 / x / 1784$

6/xii/1784

27/iv/1785

$1 / \mathrm{vi} / 1785$

$12 / \mathrm{x} / 1785$

$4 / \mathrm{i} / 1786$

20/ii/1786

1/v/1786

12/vii/1786

$17 / x i / 1786$

27/xii/1786

24/i/ 1787

22/vi/1787

$1 / x / 1787$

$10 / \mathrm{ix} / 1788$

$14 / x i / 1788$

11/ii/1789

11/xii/1789

26/i/1790

\section{Composer}

Giuseppe Barta

Giovanni

Paisiello

Giacomo Rust

Antonio Salieri

Vincenzo Righini

Stephen Storace

Antonio Salieri

Vicente Martin

y Soler

Giuseppe

Gazzaniga

Wolfgang Amadeus Mozart

Vincenzo Righini

Vicente Martin

y Soler

Stephen Storace

Karl Ditters von

Dittersdorf

Francesco

Piticchio

Vicente Martin y Soler

Antonio Salieri

Joseph Weigl

Antonio Salieri

Antonio Salieri

Wolfgang Amadeus Mozart
Librettist

Francesco Bussani

Giambattista Casti

Caterino Mazzolà

Lorenzo Da Ponte

Nunziato Porta

Gaetano Brunati

Giambattista Casti

Lorenzo Da Ponte

Lorenzo Da Ponte

Lorenzo Da Ponte

Lorenzo Da Ponte

Lorenzo Da Ponte

Lorenzo Da Ponte

Gaetano Brunati

Lorenzo Da Ponte

Lorenzo Da Ponte

Lorenzo Da Ponte

Caterino Mazzolà

Lorenzo Da Ponte

Lorenzo Da Ponte

Lorenzo Da Ponte

Note: Nearly all of this information is drawn from Otto Michtner, Das alte Burgtheater als Opernbühne: Von der Einführung des deutschen Singspiels (1778) bis zum Tod Kaiser Leopolds II. (1792) (Vienna, 1970). See also Franz Hadamowsky, Die Wiener Hoftheater (Staatstheater) 1766-1966, vol. 1: 1766-1810 (Vienna, 1966); and Otto Erich Deutsch, "Das Repertoire der höfischen Oper, der Hof- und der Staatsoper. Chronologischer Teil.” Österreichische Musikzeitschrift XXIV (1969), 400-02. 